Recepción: 17/04/2015

Evaluación: 01/05/2015

Aprobación: 15/07/2015

Artículo de Reflexión

\title{
ROSARIO REMIGIO FIORE FORTEZZA. FÍSICO, MATEMÁTICO, FRANCISCANO. APROXIMACIÓN A SU VIDA Y A SUS APORTES
}

\author{
Luis Aphranio Portilla \\ Universidad de Nariño \\ lportillas@yahoo.es
}

\begin{abstract}
RESUMEN
En 1965, el ciudadano italiano, padre capuchino Remigio Rosario Fiore Fortezza, es invitado como profesor de Física del Departamento de Ingeniería y Física, en la Universidad de Nariño, Pasto, Colombia. Durante dos décadas, realiza una notable labor académica. Para lograr su propósito pedagógico, elabora apuntes para clase (en mimeógrafo), material bibliográfico con carácter científico, con el cual pretende enseñar (y divulgar) en cada momento histórico, los avances científicos en los campos de la Física, la Matemática, la Astronomía y la Astrofísica. En el artículo, se pretende abordar aspectos humanos y de fe, del padre Fiore y hacer visible el impacto de su gestión profesoral en algunos de sus exalumnos, de diferentes generaciones de egresados de la Universidad de Nariño. Paralelamente, se efectúa una reseña histórica del estado de la región y de los avatares nacionales y mundiales, durante los años de su docencia y se describen varios antecedentes históricos de interés.
\end{abstract}

Palabras clave: Astrofísica, Astronomía, Física, Matemática, Orden de los Hermanos Menores Capuchinos. 


\title{
ROSARIO REMIGIO FIORE FORTEZZA. PHYSICIAN, MATHEMATICIAN, FRANCISCAN. AN APPROACH TO HIS LIFE AND HIS CONTRIBUTIONS
}

\begin{abstract}
In 1965 the Italian citizen Father Capuchino Remigio Rosario Fiore Fortezza, was guest professor of Physics in the Department of Engineering and Physics at the University of Nariño, Pasto, Colombia. For two decades he proved a remarkable academician. To achieve his educational purposes, he produced class notes (mimeographed), bibliographical material of a scientific nature, which aimed to teach (and report) on historical moments, along with scientific advances in the fields of Physics, Mathematics, Astronomy and Astrophysics. The article is intended to address aspects of Father Fiore's faith and humanity and to make visible the impact of his teaching methods in various alumni from different generations of graduates of the University of Nariño. At the same time, there is an historical review of the state of the region and national and global vicissitudes during the years he taught, which describe various antecedents and historical interests.
\end{abstract}

Key words: Astrophysics, Astronomy, Physics, Mathematics, Order of the Minor Brothers Capuchins.

\section{ROSARIO REMIGIO FIORE FORTEZZA. FÍSICO, MATEMÁTICO, FRANCISCANO. APROXIMANDO SUA VIDA E SUAS CONTRIBUIÇÕES}

\begin{abstract}
RESUMO
Em 1965, o cidadão italiano, padre Remigio Rosario Fiore Fortezza Capuchino, é convidado como professor de Física do Departamento de Engenharia e Física, na Universidade de Nariño, Pasto, Colômbia. Por duas décadas, ele faz um trabalho acadêmico notável. Para atingir sua finalidade educacional, prepara notas para a classe (em mimeógrafo), material bibliográfico com caráter cientista, com o qual tem como objetivo ensinar (divulgar) em cada momento histórico, os avanços cientistas nas áreas física, matemática, astronomia e Astrofísica. No artigo, a'pretensão é tratar de aspectos humanos e da fé do padre Fiore e tornar visível o impacto da sua gestão professoral em alguns de seus ex-alunos, de diferentes gerações de graduados da Universidade de Nariño. Em paralelo, se efetua um panorama histórico do estado da região e avatares nacionais e globais , é feito durante os anos de seu ensino e se descrevem antecedentes históricos de interesse.
\end{abstract}

Palavras-chave: Astrofísica, Astronomia, Física, Matemática, Ordem dos Frades Menores Capuchinhos. 


\section{INTRODUCCIÓN}

“El 14 de marzo de 1966, un capuchino alto y fornido, de presencia europea, entró en el laboratorio de Física para empezar el curso de Física experimental, con un grupo de doce compañeros" 1 . Con estas palabras, un estudiante de Física experimental en la Universidad de Nariño, evoca la figura del padre Remigio Rosario Fiore Fortezza, un capuchino italiano, que había llegado el 18 de diciembre de 1965 a Colombia, para colaborar con la enseñanza de la física en la ciudad de Pasto, en la Universidad de Nariño.

Las gestiones para convocar al padre Fiore a Pasto, fueron realizadas en 1965, por el padre Pablo de Arma, Superior de los hermanos menores capuchinos en Pasto, quien también se desempeñaba como Decano de la Facultad de Educación de la Universidad de Nariño. A su llegada a Pasto, el padre Remigio Fiore tenía 53 años y dos títulos de Doctorado, obtenidos en la Universidad de Palermo, Italia: Física Pura, en 1947 y Farmacia, en 1965.

El esfuerzo de tipo indagatorio que acompaña a la estructuración del presente artículo, es el resultado de los hallazgos reunidos en un lapso significativo de tiempo. Desde el año de 2013, se ha procurado reunir material biográfico y bibliográfico (además de realizar entrevistas), que soporten adecuadamente la investigación enfocada a perfilar los aportes científicos, sociales, culturales, humanísticos y religiosos del padre Fiore. En este sentido y para comprender en profundidad la dimensión personal del padre, es preciso efectuar una reconstrucción de diversos hechos históricos que sin duda, lo enmarcan. Complementa la pesquisa histórica, los avatares que rodearon a la Orden de los Frailes Capuchinos. De esta mirada histórica a deshilvanarse en los capítulos que siguen, no está totalmente exenta la particular mirada subjetiva: máxime si se tiene en cuenta que el investigador tuvo la oportunidad de interactuar con el padre Fiore en calidad de alumno y por un breve tiempo, como monitor. En el año de 2010, el sociólogo Alfredo Molano Bravo, se expresó así al referirse a su propio método de reconstrucción de historias de vida: Yo reivindico la subjetividad como parte esencial de la mirada histórica. Penetrar en un personaje equivale a vivirlo, y es imposible hacerlo sin una íntima fusión de sensaciones [...] De alguna manera, la lucha está en permitirse ser alojado y al mismo tiempo alojar al personaje [...] El intento biográfico nace en esa condición ${ }^{2}$. Las palabras de Molano Bravo, serán orientadoras en la indagación acerca del personaje Remigio Fiore.

1. Remigio Rosario Fiore Fortezza, Física del Canguro (Pasto: Universidad de Nariño, 1989), 2 [énfasis añadido].

2. Alfredo Molano Bravo, "La gente no habla en conceptos a menos que quiera esconderse", en: Memorias 2010, Ponencias (Pasto: Asociación para el Desarrollo Campesino, ADC, 2010), 4-5. 


\section{PERFILES DE REMIGIO FIORE Y DE LA ORDEN DE LOS HERMANOS MENORES CAPUCHINOS}

El padre Fiore nació en Monreale, Palermo, el 6 de junio de 1911 y su ordenación sacerdotal fue el 8 de junio de $1934^{3}$. Ordenado sacerdote a los 23 años, durante su larga vida, se mantiene firmemente aferrado a su convicción franciscana; misión que concluye con su muerte en 1998, a la edad de 87 años.

La Orden de los Hermanos Menores Capuchinos (Ordo Fratum Minorum Cappuccinorum, abreviado OFM Cap) más conocidos como los Capuchinos, son una reforma de los Franciscanos de la observancia (OFM) y pertenecen a la primera Orden de San Francisco. Sin querer ser fundador, Giovanni di Pietro Bernardone, más conocido como San Francisco de Asís (Assisi, 1182-1226), místico italiano y predicador, durante su juventud llevó una vida mundana. Tras una batalla entre Asís y Perugia, estuvo encarcelado un año en esta ciudad. Siendo prisionero padeció una grave enfermedad durante la cual decidió cambiar su forma de vida. Ejerce la caridad entre los leprosos y trabaja en la restauración de ruinas de iglesias. Los gastos en obras de caridad enfurecieron a su padre, que llegó a desheredarlo. Francisco de Asís, renunció a su lujosa ropa por una capa y dedicó los tres años siguientes al cuidado de los leprosos y los proscritos en los bosques del monte Subasio. Restauró la ruinosa capilla de Santa María de los Ángeles. En 1208, durante una misa, escuchó una llamada diciéndole que saliera al mundo y, siguiendo el texto de Mateo 10, 5-14, "no poseyera nada pero hiciera el bien en todas partes". Cuando regresó a Asís ese mismo año, empezó a predicar, provocando la renovación de la espiritualidad cristiana del siglo XIII. Reunió a los 12 discípulos que se convertirían en los hermanos originales de su orden, más tarde llamada la Primera Orden y lo eligieron superior. En 1212 recibió a una monja de Asís llamada Clara, en la comunidad franciscana; a través de ella se estableció la orden de las damas pobres (las clarisas, más tarde segunda Orden franciscana) ${ }^{4}$.

El testimonio evangélico de vida de Francisco de Asís fue tan impactante, que nacieron tres Órdenes: la primera, de los frailes; la segunda, de las Clarisas y la tercera, de los seglares (OFS). Después de la muerte de San Francisco, la primera Orden Franciscana (frailes), creció bastante. Con el pasar de los años se perdía aquel fervor y austeridad de los inicios y se presentaron históricamente varias reformas, buscando recuperar el espíritu vivido por el Santo de Asís; de tal modo que se multiplicaron los grupos de Frailes franciscanos; entonces el Papa León XIII unió a todos esos grupos y dejó solamente tres,

3. Manuel Zarama Delgado, "Algunos Europeos en Pasto, II Parte”, en: Manual Historia de Pasto, Tomo V, (Pasto: Alcaldía Municipal de Pasto-Oficina Municipal de Cultura, 2002), 374.

4. Biografía de San Francisco, http://www.buscabiografias.com/bios/biografia/verDetalle/4330/ San\%20Francisco\%20de\%20Asis (14 de mayo de 2014). 
los más significativos, todos con la misma regla de San Francisco y la misma espiritualidad franciscana: Conventuales, Observantes y Capuchinos ${ }^{5}$.

La historiadora Anel Hernández Sotelo, sostiene que se ha escrito muy poco sobre la Orden de Frailes Menores Capuchinos, reforma franciscana nacida en Italia hacia 1528, que perseguía el retorno al franciscanismo primitivo del siglo XIII' ${ }^{6}$. En su condición de fraile, el padre Fiore, estaba obligado a seguir la observancia de sus superiores. Se tiene conocimiento de que apenas ordenado sacerdote, inició su ministerio como Capellán militar y prosiguió, también en Palermo, con la asistencia espiritual a obreros de varias fábricas. En estas labores, hacía seguimiento a dos de las reglas de su Orden: Regla de Finalidades de atención espiritual y Regla de Finalidades caritativas y sociales. El padre Fiore, prestará asistencia a los necesitados de socorro y ayuda, como medio de que todos los hermanos, siguiendo el ejemplo de Jesús, se ejerciten en el amor a sus semejantes.

Los frailes capuchinos, surgen como la tercera gran familia franciscana. $\mathrm{Su}$ origen se desprende del tronco de los hermanos menores observantes, en 1525. Para entonces, los observantes eran ya varias decenas de miles en todo el mundo y la evolución interna y los fines apostólicos los habían llevado a una situación nueva, muy diferente de los comienzos en eremitorios y pequeños conventos. El ejemplo de la observancia del Franciscanismo con la Regla a la Letra, fue obra de Mateo Serafini de Bascio y de los hermanos Ludovico y Rafael Tenaglia. Con la mediación de la sobrina del papa Clemente VII, Catalina Cybo, obtienen mediante la bula "Religionis Zelus", el nacimiento de la familia capuchina. El papa les concedió vestir el hábito con capucho piramidal y llevar barba, como signo de pobreza, sencillez y austeridad?

\section{BREVE HISTORIOGRAFÍA DE LA ORDEN CAPUCHINA}

La Fundación y consolidación en Europa, de la Orden de los Frailes Menores Capuchinos, se lleva a cabo durante los siglos XVI y XVII. La Orden Capuchina, surge como una floreciente reforma de la primera Orden Franciscana en 1528. Los capuchinos, se extienden rápidamente por toda Italia, desplegando un admirable celo apostólico en los medios populares ${ }^{8}$. En España, a partir de 1578, se funda la primera comunidad capuchina9. Durante los años que

5. Historia de los Capuchinos en Colombia, http://www.capuchinoscolombia.com/capuchinos.html (15 de mayo de 2014).

6. Anel Hernández Sotelo. "El prodigioso hábito capuchino. Construcciones y violencia simbólica en la escritura de Zacarías Boverio”, Dimensión Antropológica, vol. 55, mayo-agosto, (2012), 121.

7. Fray Tomás Gálvez. Sitio oficial de los hermanos menores capuchinos. Los frailes de la "vida eremítica" o capuchinos (mayo 22 de 2002), http://www.fratefrancesco.org/ord/64.cap.htm (15 de mayo de 2014).

8. Manuel Castellar, Los Capuchinos en Colombia, 1888-1970 (Bogotá: Gráficas Centella, 1970), 2.

9. Castellar, 2. 
anteceden al siglo XVII, la fundación de numerosos conventos se sucede con rapidez y el incremento del número de religiosos es significativo: en 1619, constituían prácticamente un ejército de 14.000 religiosos comprometidos en todos los campos del apostolado católico, principalmente en la asistencia a los apestados y en el ministerio de la predicación popular ${ }^{\mathbf{1 0}}$.

Así, aunque históricamente, la imagen tradicional de San Francisco fue la de un hombre piadoso que tenía el don de hablar con los pájaros y con los astros, -a quienes denominó: hermano sol, hermana luna-; las crónicas lo convierten también en un santo justiciero que utilizaba el cordón de los tres votos para azotar a quienes se interponían en la expansión de la Orden. Según las crónicas de Boverio, en 1572, San Francisco de Asís, se le apareció a un hombre que se negaba a vender un pedazo de tierra a la Orden, pese a que se le ofrecía un precio justo. En esa tierra, la Orden quería construir un convento. El Santo de Asís, con el fin de escarmentarle se hace visible a "un vezino de un lugar de Aguafria de la familia de los Mafeos, [...] vestido en habito capuchino y con la cuerda que traìa ceñida, le diò tantos acotes que últimamente le obligò, no à que vendiesse la heredad, sino à que hiziessedonacion graciosa della a los nuestros"11.

El ejemplo y las observancias instauradas por Francisco de Asís, constituyen la piedra angular sobre la cual se erige la Orden capuchina. La filosofía de vida y de servicio, fue plasmada por escrito y para su difusión entre los adeptos a la Orden. Estos referentes fundamentales, son conocidos como las Reglas. Las Reglas, permiten acceder al estado de renunciamiento de las inclinaciones mundanas y hacen posible el acometer la empresa de fortalecimiento espiritual de la Orden, fundamentada en la imitación de la humildad, pobreza y castidad de Jesucristo. En vida de Francisco de Asís, constituían Reglas, las siguientes: a) Desapropio de bienes. Ningún miembro tenía posibilidades de poseer bienes individuales y los bienes que se tuvieran se donarían por caridad, b) Pobreza total incluso en los bienes inmuebles pues "la fraternidad no necesitaba ni el techo común, ni el coro común, ni siquiera la mesa común", esto es, los franciscanos no necesitarían conventos ni monasterios para predicar, c) Debían llevar un vestido sencillo y pobre que "no hiciera diferencia alguna entre sus miembros", d) Su medio de subsistencia era el trabajo y sólo en ocasiones especiales de carencia extrema, podrían recurrir a la limosna o mendicación, e) Su objetivo primordial sería la predicación popular encaminada a la conversión de los infieles, f) Espíritu constante de llevar a todos los rincones del mundo el mensaje de paz ${ }^{12}$.

10. Gálvez, Los frailes de la "vida eremítica" o capuchinos, 1.

11. Zacarías Boverio, Primera parte de las Chronicas de los Frailes Menores Capuchinos (Madrid: Carlos Sánchez, 1644), Apéndice "De la verdadera forma de hábito", 57.

12. Marcela CorveraPoiré. Estudio Histórico de la familia de Franciscanos Descalzos en la Provincia de San Diego de México, siglos XVI-XX. Tesis Doctoral en Doctorado en Historia, Universidad Complutense de Madrid, 1995, 10-12. 


\subsection{Los Capuchinos en Colombia}

Los primeros franciscanos llegaron a tierras de América en 1493, acompañando a Colón en su segundo viaje. No obstante, la presencia de los capuchinos en el Nuevo Mundo, fue tardía: se establecieron en Colombia, en 169413, durante el largo período colonial que se extendió desde 1550 a 1810.

La presencia de las misiones en Colombia y en Hispanoamérica, son el resultado directo del descubrimiento geográfico del Nuevo Mundo y del poderío otorgado por las Bulas pontificias, que entregaron a la monarquía de la Península Ibérica, un inmenso espacio en el cual expandir la cultura europea; labor que llevó sujeta la obligación de cristianizar a las poblaciones autóctonas. Entre las bulas concedidas por el Papa Alejandro VI (1492-1503) a los monarcas españoles, y a los monarcas portugueses, sobresalen: a) Inter caetera, de 3 de mayo de 1493 o bula de donación. Primera bula. Por medio de ella, el Papa establece que todas las tierras descubiertas por Colón y las que posteriormente se descubran, serán para Castilla, b) Inter caetera, de 4 de mayo de 1493, bula de partición o de demarcación, se le llama así porque modifica el sentido de la primera bula y divide el océano en dos partes, mediante una línea de polo a polo trazada a 100 leguas al oeste las islas Azores y Cabo Verde; las tierras al occidente o al mediodía de esa frontera serán para Castilla y las del oriente o poniente, portuguesas. Segunda bula. Quedó modificada por el Tratado de Tordesillas de 1494, c) Eximiae devotionis, del 3 de mayo de 1493, otorga a los reyes católicos en sus territorios los mismos privilegios que a los reyes de Portugal en los suyos. Cuarta bula, d) Dudum siquidem, del 26 de septiembre de 1493, conocida como ampliación de la donación. Quinta bula. En esta bula no se menciona para nada la segunda bula y se ratifica lo señalado en la primera bula, ampliando su concesión en cuanto señala para los castellanos las tierras que hubiera hacia la India ${ }^{14}$. Finalmente, en criterio de algunos historiadores como Molinari, las bulas Alejandrinas, a fuerza de tanto conceder terminaron por no conceder nada ${ }^{15}$, lo cual llevó a las coronas de España y Portugal a buscar la solución de los pleitos coloniales, de manera directa.

Superada la conquista del Nuevo Mundo, se abren paso en la nación Colombiana, nuevas épocas históricas: Colonia, Independencia y República. Sin embargo, entrado el siglo XX, aún los poderes públicos del Estado continúan empleando a las órdenes religiosas como eficaces agentes de colonización. En

13. Castellar, 3.

14. Antonio García y García, "La donación pontificia de las Indias”, en Historia de la Iglesia en Hispanoamérica y Filipinas (siglos XV-XIX), eds. Pedro Borges (Madrid: Biblioteca de Autores Cristianos, 1992), 33-34.

15. Diego Luis Molinari, Descubrimiento y conquista de América (Buenos Aires: Eudeba, 1964), 104 [La cursiva es del autor]. 
1927, el padre Fidel de Montclar, misionero capuchino, destinado a las misiones en el Caquetá y el Putumayo, aseveró: "El Caquetá y el Putumayo están ya en vía de ser salvados: los misioneros podrán libremente navegar por aquellos ríos, y las lanchas los llevarán rápidamente a los más apartados rincones de aquellas interminables soledades, para anunciar (la) santa ley a los que están aún sentados en la sombra del gentilismo"16.

Durante los siglos XIX y XX, el Gobierno colombiano solicita colaboración a diferentes órdenes religiosas, para la implementación de las políticas públicas. Así mismo, la fundación de ciudades misionales por las órdenes religiosas, especialmente los franciscanos, se mantuvo vigente tras la Independencia de Hispanoamérica. En la ciudad de Pasto, todas las comunidades religiosas establecidas, datan del siglo XVI, a excepción de los Jesuitas, quienes se instalaron en el siglo XVIII. En la ciudad de Pasto se establecieron las siguientes órdenes religiosas: Dominicos, Mercedarios, Franciscanos, Agustinos, Monjas Concepcionistas, Jesuitas ${ }^{17}$.

La Orden de los Franciscanos es la más antigua en Pasto.Llegaron hacia 1550 y fundaron el convento en la plazuela de San Andrés. Sus fundadores, Fray Pedro de Rodeñas y Gaspar de Valverde, iniciaron las actividades doctrinarias. En la primera mitad del siglo XVIII, los Franciscanos tenían en la provincia de Pasto, fuera del patrimonio de su fundación, la limosna que recibían de Barbacoas, consistente en una libra de oro; los vecinos tenían la costumbre de darles una fanega de todo lo que cosechaban; además poseían un molino en la ciudad que era llamado de San Francisco, y el curato de Pandiaco ${ }^{18}$.

El influjo de las numerosas órdenes religiosas instaladas desde mediados del siglo XVI en la Provincia de Pasto, determina la atmósfera que describirá tres siglos y medio después, el viajero e ingeniero Miguel Triana (18591930), luego de su recorrido por las tierras de Nariño y Putumayo, en 1906 y 1907:"Como núcleos de concentración, aparecen dispersas en el Valle de Atris una veintena de capillas, de torres cuadradas cubiertas de teja, donde penden las campanillas de voz chillona, que sirven de lengua a la parcialidad agrupada a su contorno: el toque de alba, para saludar el día; el de avemaría, para suspender las labores campestres y alabar a Dios y el toque de ánimas, para recordar a los antepasados, son los únicos signos del lenguaje metálico de la

16. Fidel de Montclar en Carta al doctor don Antonio José Uribe, fechada Bogotá 23 de diciembre de 1927. Citado en el libro del padre capuchino Pacífico de Vilanova, Capuchinos catalanes en el Sur de Colombia. (Barcelona: Imprenta Myria, 1947), 15.

17. Gerardo León Guerrero Vinueza, "Análisis socioeconómico de Pasto a finales del período colonial", en: Pasto 450 Años. Historia y cultura, compilador Alvaro Yie Polo (Quito: Instituto Andino de Artes Populares del convenio “Andrés Bello" y Universidad de Nariño, departamento de Filosofía y Humanidades, 1988), 146-147.

18. José Rafael Sañudo, Apuntes sobre la historia de Pasto. La colonia bajo la casa de Borbón. (Pasto: imprenta La Nariñense, 1940), 29. 
parcialidad, pronunciados desde lo alto del campanario entejado de la capilla rústica"19. Miguel Triana, anota cómo la tradición católica y el celo religioso, se articulan en elementos constitutivos de la personalidad de la heterogénea población de Pasto.

Antes de proseguir, es preciso anotar que en 1892 el Estado de Colombia promulga la Ley 72, la cual autoriza el establecimiento de misiones en su territorio y además, otorga a los misioneros facultades extraordinarias. Las misiones se establecen en primer lugar en la Orinoquia y la Amazonia, pero también en el Chocó, la Sierra Nevada de Santa Martha, la Guajira y partes de la región baja del Río de la Magdalena. Las misiones garantizan desde finales del siglo XIX hasta entrado el siglo XX, la presencia de la iglesia católica en territorios con ausencia del Estado: "Son protagonistas de la historia capuchina, además de la serie numerosa de misioneros anónimos y de la galería de misioneros de gloriosa recordación, los indígenas de la Guajira, Sierra Nevada, Motilones, Sibundoyes y Amazónicos"20. La misión del Caquetá, se crea en 1904 y tiene para Colombia un alto valor político: el de afirmar su soberanía sobre extensas regiones que le eran disputadas por el Perú. En palabras del padre Pacífico Vilanova, "con su sola presencia, los misioneros Capuchinos, estandarte de civilización cristiana y colombiana, frenaban las ansias expansionistas peruanas"21.

\section{ANTECEDENTES ECONÓMICOS, POLÍTICOS Y SOCIALES DE LA REGIÓN NARIÑENSE, ANTES DE 1965}

En el capítulo anterior, se realizó una rápida referencia a Miguel Triana. Como ingeniero, Triana argumenta que una "constitución política de carácter científico", es imposible de realizar en un país con carencias de transporte y movilidad. En la década de 1960, la caracterización de las carreteras y caminos de la región aún continuaba rezagada del desarrollo, dado que gran parte de las comunicaciones nariñenses se hacían a través de los tradicionales caminos de herradura, los cuales aún eran mayoritarios: "se puede decir entonces que las carreteras sólo tienen su comienzo entre 1950 y 1960"22. De esta manera, en el momento del arribo del padre Remigio Fiore a Pasto en 1965, recién la ciudad iniciaba la transición hacia la modernización, aparejada con el siglo XX.

La incorporación de las políticas públicas en esta región sureña, se rezagaron por múltiples dificultades: la compleja geografía, la insuficiente infraestructura

19. Miguel Triana. Por el sur de Colombia. Excursión pintoresca y científica al Putumayo (París: Garnier Hermanos, 1908), 76.

20. Castellar, 4.

21. Vilanova, Capuchinos catalanes en el sur de Colombia, 238.

22. Guillermo Alfredo Narváez Ramírez, "Aspectos fundamentales de la economía de Pasto y Nariño", en: Pasto 450 Años. Historia y cultura, compilador Alvaro Yie Polo (Quito: Instituto Andino de Artes Populares del convenio "Andrés Bello" y Universidad de Nariño, Departamento de Filosofía y Humanidades, 1988), 258. 
vial y las discrepancias políticas en diferentes momentos históricos. Esta región se resistió a la causa independista y por lo mismo, no contó con las simpatías de la clase dirigente del Estado. En esta región, casi todo llegó con retraso, incluyendo las ideas y la implantación del proyecto modernizador que desde finales del siglo XIX regía los destinos de América Latina. La primera carretera al Sur, inició en 1906 y concluyó 26 años más tarde, en plena guerra con el Perú, provocada por un conflicto de delimitación fronteriza. En 1907, se consideró de vital importancia la comunicación entre el Huila y el Cauca, en función de lo cual se celebró un contrato para la apertura de un camino que debía partir de Palermo y terminar en la Pradera. En correspondencia con ese objetivo, se decretó un auxilio para la vía de Las Papas que comunicaba los pueblos del sur del Huila con los del sur del Cauca y con Pasto, vía que por lo pronto, no era más que una senda mediante la cual se hacía un difícil comercio de ganado y de algunos artículos ${ }^{23}$.

La modernización fue tanto más difícil, con el telón de fondo de un país con antecedentes de gobiernos inestables y pugnas constantes. Durante el siglo XIX, la república que hoy conocemos como Colombia, tomó distintos nombres y se orientó bajo convulsos cauces políticos: Nueva Granada (18321857); durante este período, en 1844, volvieron los jesuitas (que habían sido expulsados durante 77 años), llamados por el gobierno, con el fin de atender la evangelización de las denominadas tribus salvajes y cubrir labores de enseñanza; Confederación Granadina (1858-1961); Estados Unidos de Colombia (1863-1885). En este escenario de confrontaciones permanentes entre connacionales, hace entrada en los albores del nuevo siglo, la práctica de las reducciones en los territorios ubicados en la periferia del país y ocupados por los indígenas: "Reducir a poblaciones fijas a los indígenas errantes. El fomento de las Misiones para la reducción y civilización de los indígenas, procurando el establecimiento de poblaciones fijas." ${ }^{24}$ A finales del siglo XIX, el Gobierno colombiano firma en Roma un convenio, garantizando el libre establecimiento de las Órdenes religiosas en su territorio. La decisión, permite a los capuchinos retornar al país por distintos puntos geográficos: unos por el norte (Guajira) y otros por el sur (Túquerres) en 1888, luego de un largo período de ausencia. Al concluir la gesta independentista de 1810, los capuchinos fueron expulsados y deportados a sus respectivos lugares de origen, en $1818^{25}$.

Durante los años de hegemonía misionera, el poder eclesiástico en la ciudad de Pasto, derivó su sustento de las rentas que sus bienes muebles e inmuebles suministraban. Paralelamente, la curia desarrolla actividades económicas complementarias en molinos, tejerías y talleres artesanales; además de la producción agrícola y pecuaria (ganadería, fundamentalmente).

\footnotetext{
23. Gaceta del Huila, Neiva, 19 de junio de 1907 [énfasis añadido].

24. Entre comillas, palabras expresadas en 1915 por el padre capuchino Fidel de Montclar, Prefecto de las misiones de Putumayo y Caquetá. En: Vilanova, Capuchinos catalanes en el sur de Colombia, 20.

25. Castellar, 4.
} 
Por otra parte, existían las "rentas eclesiásticas" como: las limosnas, el pago de los servicios catequísticos y ceremonias religiosas, los diezmos. Los diezmos consistieron en una cesión o donación de particulares a la iglesia, de una parte de la producción económica ${ }^{26}$. Ocasionalmente, la iglesia recibía también donaciones generosas de titulaciones (bienes inmuebles, muebles, dinero) ${ }^{27}$.

Por consiguiente, en el aspecto urbano, la ciudad de Pasto en 1965, se asemeja mucho a la descripción que en 1942, en el quinto centenario del Descubrimiento de América, realizara el historiador José Rafael Zarama: "La ciudad de Pasto, capital del Departamento de Nariño y del Distrito de su nombre, está situada a (...) 2490 metros sobre el nivel del mar. Los vientos dominantes en la región soplan durante gran parte del año, en dirección SE. y NW. Su clima medio es de 15 gr. c.; (...) La ciudad se extiende de Oriente a Occidente y de S. E. a N. O. al pie del volcán Galeras y en los términos del hermoso valle de Atrís, circundado de colinas de exuberante vegetación, sobre las cuales se destacan numerosos caseríos (...)"28.

Históricamente, Colombia ha sido un país con tradición de "puertas cerradas" para los inmigrantes. La presencia de los italianos en Colombia, constituye un grupo mayoritario dentro de las pocas colonias distintas a las tradicionales aborígenes, hispánicas, africanas y mestizas. Italia, ha sido tradicionalmente un país de emigrantes. Los investigadores Zeffiro Ciuffoletti y Maurizio dell' Innocente, señalan que a partir de 1960, en Italia tomó vida un fenómeno migratorio que por sus "características cuantitativas y sus peculiaridades cualitativas tenía pocos elementos en común con la migración tradicional. Este éxodo no podía confundirse con el fenómeno de la migración política que caracterizó los años que antecedieron a la unidad de Italia, aun cuando fue precisamente éste el que trazó el camino a la nueva migración. Es más, fue el entrecruzarse la migración política con la laboral, que caracterizó el éxodo de los italianos en los primeros años que siguieron a la unificación de la península"29. A diferencia de sus connacionales italianos, el padre Remigio Fiore no emigra por motivos económicos o políticos. Su llegada a Colombia, está motivada por el cumplimiento de una misión académica, invitado por el padre capuchino Pablo de Arma.

26. Gerardo León Guerrero Vinueza, “Análisis socioeconómico de Pasto a finales del período colonial”, en: Pasto 450 años. Historia y cultura, 149.

27. El terreno donde se construyó en Pasto, la Parroquia de Santiago Apóstol y el convento de los Capuchinos, fue donado el 27 de marzo de 1894 por las señoritas Dolores y Rosario Santacruz a la Diócesis de Pasto. Consta en placa de mármol grabada, ubicada a la entrada del Convento.

28. José Rafael Zarama. Reseña Histórica (Pasto: Imprenta del Departamento, 1942), 179-180.

29. Zeffiro Ciuffoletti y Mauricio dell' Innocente, "L'Emigrazione nella storia d' Italia 1869-1975", en: Acerca de las migraciones centro-europeas y mediterráneas a Iberoamérica: aspectos sociales y culturales, eds. Moisés Minambres (Sin ciudad de edición, 1995), citado en: Armando Silva, Cultura italiana en Colombia. Reflexión sobre etnias y mestizajes culturales (Bogotá: Tercer Mundo Editores e Istituto Italiano di Cultura, 1999), 7. 


\section{BIOGRAFÍA DEL PADRE REMIGIO FIORE (1911-1965), ANTES DE SU VIAJE A COLOMBIA ${ }^{30}$}

Hijo de Innocenzo Fiore y Giuseppina Fortezza. Hogar conformado por cinco hermanos. Realizó sus estudios primarios, en el Colegio de María Piazzeta, en San Giuseppe, Monreale, al sur de Palermo (Italia). Los estudios de Gimnasio (secundarios) los efectuó en el Seminario Seráfico Casa Santa en Monreale, que constituye el primer seminario seráfico anclado en el sur de Sicilia, fundado en 1923 por orden del Ministro General de la orden religiosa Capuchina, bajo la dirección del padre Bernardo de Andermatt, de origen Suizo. El seminario es el establecimiento religioso en donde se forma a los aspirantes al sacerdocio. Seminario significa semillero, del latín seminarium, derivado de semen o semilla. La palabra seminarium fue usada oficialmente por primera vez en el Concilio de Trento (1545-1563). El Concilio de Trento estableció para todas las diócesis la obligación de erigir un seminario destinado a la formación de sus sacerdotes. El decreto, aprobado en julio de 1556, se convirtió en la carta magna de los seminarios. Los candidatos para ingresar a los seminarios debían ser hijos legítimos de matrimonio canónicamente constituido y tener al menos, doce años de edad, un mínimo de formación intelectual y el deseo sincero de dedicarse al servicio de la iglesia. ${ }^{31}$ Los estudios fundamentales radican en Filosofía y Teología, estudios que concluyó luego del noviciado. A continuación, realizó los estudios correspondientes para obtener consecutivamente: profesión temporal, profesión perpetua, subdiaconado y diaconado; estudios que finalizaron en 1934, año en el cual se lleva a cabo su ordenación sacerdotal.

Inició su carrera como profesor antes de culminar sus estudios en el Seminario. Entre 1934 y 1938, fue profesor de matemáticas y francés en el seminario de Caltanissetta. Entre 1938 y 1940, realiza servicio apostólico en Castelvetrano, una localidad al sur de Sicilia. En los tres años siguientes, de 1940 a 1943, -durante la segunda guerra mundial-, permanece en la Base Militar de Castelvetrano, como Capellán Militar. En junio de 1940, Italia entra a la guerra: "Ilegué a Nápoles, mientras bombas de los aliados llovían sobre la ciudad, que también se estremecía por el volcán Vesubio que vomitaba ríos de lava, han sido momentos tristes" ${ }^{\prime \prime 2}$. En ese año, se reglamenta una Ley de Mussolini que obliga a todo sacerdote dedicado a la enseñanza en los seminarios, a obtener el título de Doctor en la materia que viene trabajando. El provincial del Seminario de Caltanissetta, padre Gaetano di Castellammare envió a Remigio Fiore y a

30. Datos Biográficos extraídos de Rosario Remigio Fiore Fortezza. Curriculum vitae (Pasto: 1996). Documento en 9 páginas, facilitado al investigador por el padre capuchino Evaristo Acosta Maestre, en el año 2013.

31. Pedro Mendoza, Mi memoria histórica (1948-1988) (Alicante: Ediciones Pedro Mendoza, 2010 ), 35.

32. Fiore, Curriculum vitae, 3. 
otros cinco compañeros seminaristas, a cursar estudios en la Universidad de Palermo donde Remigio Fiore se inscribe en Física Pura: "allí por cuatro años, cumplí mi misión bajo la dirección del profesor Enrico Mèdi”33. Enrico Mèdi34 (1911-1974) lo quería como su sucesor en la enseñanza de la física en la Universidad de Palermo.

A la par con los estudios de la física, ofició de sacerdote. En su labor pastoral, fue capellán militar en la base aérea de Castelvetrano, Sicilia, hasta 1943. En ese año,retorna a la ciudad de Palermo donde realizó asistencia espiritual a los obreros de industrias y de las minas de azufre, hasta 1948: “(..) empecé a trabajar con alegría y libremente por la lucha electoral para las elecciones políticas en Italia pues, no se habían hecho desde hacía 21 años de dommaciótt (sic) [dominación] fascista”35. En los dos años siguientes, hasta 1950, se dedicó a la misión mariana: “con una imágen de la Madona di Fátima en la arquidiócesis de Monreale, Cefalú y Palermo"36.

33. Fiore, 2.

34. Biografía Profesional de Enrico Mèdi. Asistió a la primera Universidad de Santa María de los padres Marianistas y luego, al Instituto Massimo jesuita. En 1930, se matriculó en el programa de posgrado en física, con la tesis discutida por Enrico Fermi, en la que se abordó cuestiones relacionadas con el reciente descubrimiento del neutrón por James Chadwick. Después de graduarse, se mantuvo en el instituto, especializándose en física terrestre, bajo la dirección de A. Lo Surdo. En 1938, obtiene la cátedra de física terrestre y enseña física experimental en la Facultad de Arquitectura de Roma. En 1942, ganó el concurso para la cátedra de física experimental en la Universidad de Palermo. El armisticio de 1943 y la posterior ocupación alemana de Roma, le alejan temporalmente de la academia. La producción científica de Mèdi, se compone principalmente de artículos publicados por el Instituto Nacional de Geofísica (ING). Entre ellos, se mencionan: la polarización de la luz cuando es dispersada por la atmósfera y pistas para la evolución previsible del estado del tiempo (Roma, 1939), encuesta Gravimétrica en Sicilia, Anales de Geofísica, método para la medición absoluta de la aceleración gravitacional. El rotogravímetro, atenuante campo magnético centro-norte en Sicilia, (trabajo conjunto presentado por Mèdi, Giorgi y Molina). Antes de 1940, algunas de sus investigaciones se divulgaron en varios idiomas y dieron origen a la creación del radar y la identificación de los fenómenos de la magnetosfera, asociada a los cinturones de Van Allen. Desde 1949 hasta su muerte, asumió la Dirección del ING. El ING, se había convertido en un centro de investigación científica en el campo de la física de la tierra. Mèdi, con su equipo del observatorio de geofísicos de Italia, realizó trabajos constantes en campos como la actualización del mapa de las zonas sísmicas, la investigación en meteorología a favor de la agricultura y la explotación de la energía solar. En 1950, elaboró un proyecto para la creación de un centro para la investigación de la Bio-física, como punto de encuentro entre las ciencias biológicas y médicas, por un lado y el mundo de la física teórica y experimental, por el otro. En 1955, obtuvo la transferencia de la Universidad de Palermo a la de Roma, para ocupar la presidencia de la geofísica en la Facultad de Matemáticas, Física y Ciencias Naturales. Entre 19541955, en los albores de la difusión televisiva en Italia, fue una de las primeras estrellas de la pequeña pantalla, en una cita semanal dedicada a los descubrimientos científicos, llamado Las aventuras de la ciencia.

En 1958, Italia lo nombró como su Vicepresidente y Comisario de la Comisión Europea de Energía Atómica (Euratom). De vuelta en Italia, se dedicó, además de la actividad científica en el ING de la Universidad de Roma, a dictar conferencias de gran prestigio en el mundo católico italiano.

Enciclopedia Treccani. Dizionario Biográficodegliitaliani. "Enrico Mèdi", Vol. 73, (2009) http://www. treccani.it/enciclopedia/enrico-medi_(Dizionario-Biografico) (7 de abril de 2014).

35. Fiore, Curriculum vitae, 4.

36. Fiore, Curriculum vitae, 4. 
En 1950, en Palermo, reconstruye el Grupo Scout PA 21, con el cual realiza excursiones:

la primera que realicé en 1959, cuando cumplía 25 años de vida sacerdotal, recorrimos la península itálica desde Palermo (... ) corriendo (sic) las famosas vías romanas (...) y visitando oportunamente todos los museos que encontrábamos utilizando un tiquete que nos había regalado el gobierno italiano. (...) Conmigo viajaban 30 jovencitos llevando en el bus la estufa de 10.000 bujías que nos daba la facilidad de hacer un almuerzo en una hora. Los campin (sic) que nosotros utilizábamos para descansar, comer, etc., etc., estaban marcados en un mapa bien estructurado y se encontraban a lo largo de las carreteras nacionales (...). El segundo viaje, internacional, lo hemos realizado en 1960, recorriendo la Via Apia desde Nápoles hasta Veintimilla y siguiendo las vías maravillosas de Francia ${ }^{37}$.

Durante los años de sus estudios de Física en la Universidad de Palermo, se desata en el mundo la persecución a la iglesia católica. El pontificado del Papa Pío XII (1939-1958), coincidió con la segunda guerra mundial e inicios de la Guerra Fría y aumento de la descolonización europea. Durante esta época, la iglesia católica tuvo que encarar la persecución bajo los regímenes fascista y comunista. En Alemania, la política y el régimen de Hitler fueron cuestionados por la iglesia católica abiertamente. El Vaticano editó dos encíclicas, oponiéndose a las políticas de Mussolini y Hitler. En represalia, los nazis iniciaron un programa de eliminación de la influencia de la Iglesia. El presidente de la acción católica de Alemania, Erich Klausener, fue asesinado de un disparo en la Noche de los Cuchillos Largos y todo su personal, enviado a campos de concentración. Más de 300 monasterios y otras instituciones fueron expropiados por la SS, la policía nazi. A lo largo de la historia, los institutos religiosos han sido objetivos visibles y vulnerables en tiempos de conflicto y lucha. En todos los países europeos, en diferentes momentos, las casas, conventos o monasterios fueron saqueados, quemados o destruidos. El comienzo del Pontificado de Pio XII, coincidió con el fin de la Guerra Española, en la cual, además de miles de fieles, fueron asesinados 4184 sacerdotes, 2365 religiosos y 283 religiosas en un período de tres años ${ }^{38}$.

En 1961, el padre Fiore realiza un viaje internacional sobre el que recordaba:

37. Fiore, "Curriculum vitae", 9.

38. Wikipedia, la enciclopedia libre. Persecuciones a la Iglesia católica en la Segunda Guerra Mundial y a Pío XII (Sin ciudad, Wikipedia, 2014), http://es.wikipedia.org/wiki/Persecuciones_a_la_Iglesia_ Cat\%C3\%B3lica_en_la_Segunda_Guerra_Mundial_y_a_P\%C3\%ADo_XII (15 de junio de 2014). 
salimos desde Palermo pasando por Suiza, Holanda, Dinamarca (Copenhague) donde comimos cerezas. Lubeg (Alemania), esta ciudad en la frontera alemana-rusa pasando por Viena y parándonos a visitar el fiunoso (sic) [famoso] DEUTSCHE MUSEUM con su maravilloso PLANETARIO: nos hemos quedado ahí todo el día, para visitar esta maravilla humana que recoge en una visión maravillosa, todos los productos de la ciencia, la historia de la humanidad, etc. Llegando a Palermo cantando alegremente ${ }^{39}$.

Por orden del Superior provincial Casianno de Salemi el padre Fiore, en 1962 inicia estudios de Farmacia a nivel doctoral, en la Universidad de Palermo. Sus superiores, necesitaban un Director para atender la Farmacia de los padres Capuchinos en Palermo. En este año, viaja a Maratona (Grecia) con un grupo de 30 scouts de Palermo: "esta vez con el bus salí de Palermo hasta Brindisi y allí nos embarcamos en una nave italiana que viajaba de Brindisi a Corfú, continuamos después viajando por tierra a Pairas, Corinto, Atenas, Maratona, Edime, Estambul."40

Durante los años de 1950 a 1965, el padre Fiore se desempeñó como Capellán de los obreros de la ACU:

con esta actividad yo tenía la posibilidad de penetrar en los lugares de trabajo y celebrar la misa para aumentar la fe de los obreros y no cayeran (sic) en las manos de los comunistas ${ }^{\mathbf{4 1}}$-y Capellán del hospital psiquiátrico de Palermo-, donde se curaban 2.000 enfermos mentales provenientes de Sicilia, Italia y Africa Septentrional. La actividad primaria era la asistencia religiosa, misas, confesiones, procesiones, eucaristías, etc. y buscando animar la vida de estos ambientes tristes $\mathbf{4 2}$.

En los primeros días de diciembre de 1965, el padre Fiore recibe la orden de viajar a Colombia para cumplir con el ministerio de la enseñanza. En la Universidad de Nariño, se encontró con la organización del Instituto Técnico Agrícola (ITA), estructurado en Departamentos Académicos. Cada Departamento, integrado por un conjunto de ciencias afines. Al frente del Departamento, está el Profesor-Jefe, encargado de la organización de la enseñanza y la coordinación de los programas de investigación. En esos años, el ITA contaba con los siguientes Departamentos académicos: Biología Química y Geología, Agronomía y Suelos, Matemáticas y Física, Ingeniería, Economía Agrícola, Zootecnia. En el Departamento de matemáticas y física, eran profesores, los italianos Nicolás Civetta Arzayús (Análisis estadístico y Análisis matemático I y II), Bruno Giorgio Grossi (Física I y II) y José María Trujillo

39. Fiore, Curriculum vitae, 5.

40. Fiore, Curriculum vitae, 5.

41. Fiore, Curriculum vitae, 6.

42. Fiore, Curriculum vitae, 8. 
(Geometría I y II) ${ }^{43}$. Otros profesores extranjeros, laboran en la Universidad: el padre capuchino Pablo de Arma y los españoles, Federico Povedano y Melchor Pozueco Rodríguez.

\section{PRESENCIA DEL PADRE CAPUCHINO REMIGIO FIORE EN PASTO (DICIEMBRE 1965-1998)}

En introducción al libro Cultura Italiana en Colombia, reflexión sobre etnias y mestizajes culturales:

a Colombia han llegado italianos de altas cualidades educativas, estéticas o científicas, lo cual compensa su reducido número de emigrantes, y que ello ha favorecido al país; también se argumenta que su modo de interactuar con los colombianos ha sido íntimo y familiar y que, en consecuencia, su adaptación ha sido fácil y congruente. Esas razones y muchas otras de similar consenso nos permiten deducir porqué su presencia ha sido tan provechosa $^{44}$.

Al momento dellegar a la ciudad de Pasto, la trayectoria personal y académica de Remigio Fiore era la de un hombre portador de un valioso equipaje cultural y humanístico. Colombia, durante los siglos XIX y XX, desarrolló políticas cerradas frente a la inmigración de grupos foráneos, lo cual desestimuló al país como lugar de destino de migrantes.

Luego de dos años de trabajo docente, desde 1968 y hasta 1974, Remigio Fiore es nombrado Jefe de Departamento de Matemáticas y Física de la Universidad de Nariño:

en 1968 la Universidad me envió como representante al Primer Congreso Latinoamericano de Física en Ciudad de México (...) Cuando nombraron como rector de la Universidad a Luis Eduardo Mora, tuve la ocasión de encontrarme con él para sugerir la compra de un laboratorio de física. Él me dijo textualmente: "Descríbame minuciosamente todos los aparatos y los compraremos" y así la universidad tuvo a su disposición aparatos para realizar experiencias en los campos magnéticos y eléctricos, aparatos de medición de radiaciones nucleares. Con él hemos hecho un derrotero para enviar al extranjero, jovencitos a perfeccionarse oportunamente en física y matemáticas. De esta preocupación son los alumnos que estuvieron en Estados Unidos y Chile y que posteriormente se convirtieron en profesores de la Universidad. En 1974 tuve que renunciar como Jefe de Departamento, para servir a la Viceprovincia de Colombia Occidental, pero seguía dictando clases ${ }^{45}$.

43. Universidad de Nariño. Prospecto General de la Universidad de Nariño (Pasto: Intergráficas, 1963), 3756.

44. Silva, Cultura italiana en Colombia. Reflexión sobre etnias y mestizajes culturales, XIII.

45. Fiore, 7. 
Las actividades de Remigio Fiore como Misionero Capuchino en la ciudad de Pasto son múltiples: Maestro de Novicios, entre 1975 y 1976, forma a jóvenes provenientes de las viceprovincias capuchinas de Bogotá, del suroeste colombiano, de México, de Nicaragua y de Venezuela. Desde 1978 a 1981, durante dos períodos, se desempeña como Viceprovincial de Colombia Occidental:

en este período establecí una casa en Medellín. Con una carta escrita al arzobispo de Medellín, la permanencia de los Hermanos en Bello quedó completamente arreglada y se comenzó a trabajar en la construcción de la nueva casa allí donde estaba la anterior edificación. En la casa de Buga hemos preparado todo para que en ella se pudiera tener una casa de convivencias y albergar allí 50 personas. También se construyó el kiosko para dictar conferencias ${ }^{46}$.

Desde su llegada a Pasto en diciembre de 1965 y hasta 1986, se desempeña como Capellán del Hospital Psiquiátrico del Perpetuo Socorro.

En los párrafos subsiguientes, se procurará compaginar la memoria histórica del padre Fiore, presente en la narratividad de cuatro de sus exalumnos en la Universidad de Nariño. La investigación efectúa recolección de datos sobre el profesor Fiore, fundamentado en historias de vida. Los datos, se obtuvieron de entrevistas y testimonios tanto orales como escritos. El elemento clave de los datos narrativos, lo constituye la experiencia personal de los actores directos.

\subsection{Testimonio Uno (Apartes)}

Tuve la fortuna de conocer al Dr. Remigio Fiore en la década del 70 cuando estudiaba en la Universidad de Nariño Física y Matemáticas. Fue mi profesor de Física Moderna, Física Teórica, y especialmente, de Astronomía. Recuerdo con mucho cariño sus clases: era muy preciso y claro en las explicaciones y gustaba de contar en ellas, muchas anécdotas de su vida profesional. Dictaba las clases mezclando palabras italianas con españolas. (...) deseaba que todos los alumnos comprendieran perfectamente lo expuesto en clase y por eso en vista de que a veces no se conseguía en esa época libros adecuados (...) él se encargaba de redactar conferencias y nos las regalaba y que poco a poco, le sirvieron de base para escribir algunos de sus libros. Le gustaba que los estudiantes participen mucho en sus clases y por eso, eran obligatorias las exposiciones. (...) Me fascinaba escuchar sobre todo su cátedra de astronomía. Yo había estudiado en forma autodidacta desde muy temprana edad la astronomía y tenía muchos vacíos en varios aspectos científicos. Cuando me matriculé en Física, esperé con gran ansiedad la llegada del sexto o séptimo

46. Fiore, 8 . 
semestre, donde estudiaría formalmente la Astronomía y tuve la gran suerte de tener como profesor al Doctor Remigio Fiore (...) Como homenaje a su labor científica, me he propuesto a recuperar la materia de Astronomía que mentes ciegas del departamento de Física, la eliminaron del plan de estudios ${ }^{47}$.

\subsection{Testimonio Dos (Apartes)}

[...] El padre conocía el valor del tiempo y el respeto al tiempo de los demás. (...) Como científico, el padre quería a la naturaleza, era un lector de los fenómenos de la naturaleza (...) muy riguroso con el proceso científico [...] ${ }^{48}$

\subsection{Testimonio Tres (Apartes)}

Yo creo que fui monitora en el 67, en matemáticas generales, y una de mis funciones era corregir los exámenes; porque imagínese esa montonera; eso era para los primíparos y, los primíparos eran doscientos. [...] Pero el padre tenía una manera de corregir rapidísima (...) pero él era rapidísimo, porque me decía, "vea jovenchita aquí hay un error inútil, rever, mire, un error inútil, rever, ya no más". 0 un error aritmético, en el que dice: " 2 por $3=5$ ".

Entrevistador: Finalmente, ¿las notas de él eran cero o cinco?

Respuesta: Nooo, nunca iban a ser cincos. Eso, eran bajísimas, bajísimas (...) Era muy estricto, que le llamaremos ahora... (sic) muy exigente, muy riguroso, hasta con el mínimo detalle; o sea, buscaba la perfección: no admitía el mínimo error, entonces era muy complicado con él, las notas eran muy bajas.

$E$ : Bueno, esa parte de la monitoría, ¿la Universidad le pagaba a usted?

$R$ : Eso si no recuerdo, tal vez creo que no... No, era ad honorem, era como un reconocimiento, era un reconocimiento académico.

(...) una vez, fue una lección que nunca se nos olvidará: teníamos un examen parcial, el primer examen parcial que teníamos con él, y resulta que no entendíamos, -que no, pues, no entendíamos-, verdaderamente no entendíamos; además, había una serie de problemas que no podíamos resolver. Teníamos dificultades y, (...) me llaman los compañeros y me dicen: mira Alicia, digámosle al padre que nos aplace el examen, nosotros no hemos alcanzado a estudiar. Y yo les dije: sí, yo también estoy de acuerdo, porque yo también,

47. Entrevista a Quijano Vodniza, Alberto, Director del Observatorio Astronómico de la Universidad de Nariño y miembro de la Sociedad Americana de Astronomía. Investigador en astrofísica y astronomía, Maestría en Física de la Universidad de Puerto Rico, Pasto, 9 de mayo de 2013.

48. Entrevista a Cabezas, Pedro Pablo, Licenciado en matemáticas y Física, segunda promoción de egresados del Programa. Profesor jubilado de la Universidad de Nariño, fue Decano de la Facultad de Educación en 1979, año en que el padre Fiore publica el artículo "Balanzas Planetarias" en la Revista Meridiano, Órgano de la Facultad de Educación de la Universidad de Nariño, Pasto, 8 de marzo de 2013. 
tampoco estoy preparada para el examen. Le fuimos a decir que nos aplazara el examen [el padre respondió] no, el examen es a tal hora, en tal lugar. Entonces, los compañeros insistieron en que no nos presentemos. Ya llegamos al examen (sic) y, cuando llegaron los de Agronomía, también habían tenido el mismo pensamiento, la misma idea, y alguien fue y le dijo al padre (sic) y dijo: No. Entonces, alguien dijo: no nos presentemos. Y como no estábamos preparados, salgámonos y nos salimos todos... el padre nos puso cero cero $(0.0)$ a todos. Todo el mundo decía: noooo..., pues, cero a todos, noooo. Pero él era un hombre estricto, exigente. Obviamente un hombre que conocía la ciencia, era un tipo muy estudioso. (...) Por ejemplo, eso de ponernos ceros, puso doscientos ceros, que todo mundo decía: doscientos ceros. No lo hace nadie. Nosotros éramos diez de la Facultad de Educación, el resto era de allá [Facultad de Agronomía] ${ }^{49}$ y, efectivamente, pues, los decanos, el padre de Arma y el de Agronomía -creo que ya era Luis Eduardo Mora el decano de Agronomía-50, le dijeron, pues, que no le podían recibir esas libretas con los doscientos ceros; él les dijo entonces: si no me las reciben entonces aquí está mi carta de renuncia: la llevaba lista. Entonces, le dijeron: no, padre, guarde su cartica.

Era una autoridad en su ciencia y en su conocimiento, yo creo que pedagógicamente estaba enmarcado en el concepto de la pedagogía y en la educación de su época, ¿no?: el maestro es todo, el maestro es el que sabe, el maestro es que pone la disciplina, el maestro es el que tiene el conocimiento $y$, el estudiante, pues, el que va a aprender, que casi no tiene derecho a nada.

$E$ : Cuando usted terminó, ¿cuántos terminaron más o menos? R: Nosotros en nuestro grupo éramos cuatro.

$E$ : ¿En qué año ingresa como estudiante a la Universidad? R: En el 65 [1965].

$E$ : Y como profesora, ¿en qué año? R: En el 69 [1969] ${ }^{51}$.

\subsection{Testimonio Cuatro (Apartes)}

Sin embargo, teníamos una pequeña dificultad: el profesor no dominaba el español. Así que él llegaba a la clase a leer sus apuntes de Física y trataba

49. Como primer Decano de la Facultad de Ciencias de la Educación ad honorem fue designado el doctor Luciano Mora Osejo, quien también desempeñaba el cargo de Jefe del Departamento de Física y Matemáticas. El padre Fiore, como profesor de matemáticas, integraba a los estudiantes de Agronomía y de Física y Matemáticas, en una misma hora-clase. Por esta razón, el grupo es tan numeroso.

50. Luis Eduardo Mora Osejo. Doctor en ciencias naturales de la Universidad Nacional. En la Universidad de Nariño fue Jefe del Departamento de Biología (1961-1965) y Decano de la Facultad de Ciencias Agrícolas (1961-1965), Rector de la Universidad (1971-1972). En esta rectoría, mediante gestión del padre Fiore, se dotó al laboratorio de Física de la Universidad, con equipos europeos, en su mayoría alemanes.

51. Entrevista a Muñoz Espinosa, Alicia, profesora jubilada de la Universidad de Nariño, monitora ad honorem del padre Fiore, única mujer exalumna del padre Fiore que llegó a ser docente en la Universidad de Nariño. Pasto, 25 de febrero de 2013. 
de hacernos entender las fórmulas que con lujo de detalle había preparado. A veces, ni siquiera comprendíamos lo que quería decir, pero nos servía de consuelo el saber que más tarde lo entenderíamos, ya que todo venía expresado con formulaciones de alta matemática.

Nuestro aliciente y nuestra defensa eran la consulta bibliográfica y la discusión en grupo. Uno que otro libro especializado, se tenía en la biblioteca. Muy pocas veces se realizó alguna prueba escrita. Todas las clases de Física se desarrollaban en el laboratorio y si tenía que durar una hora y cincuenta minutos, así se cumplía.

Gracias a la insistencia del padre Fiore, la universidad adquirió un buen laboratorio de Física (para esa época) y unos cuantos libros especializados.

Se retiró de la universidad en 1987, después de trajinar más de veinte años por los laboratorios de su especialidad. (...) Regido por su lema "No hay tiempo que perder"siempre estaba inquieto y emprendía cualquier nuevo trabajo. ${ }^{52}$

Los apartes de los testimonios atrás citados, se enmarcan dentro de la categoría: riqueza histórica en hechos y acontecimientos. En el hilo del tiempo, las reminiscencias de los exalumnos articulan el acontecer de Remigio Fiore. Los testimonios narrados, posibilitan extraer del contexto histórico, la vivencia, tal y como la gente percibió y entendió la dimensión humana, social, científica y religiosa del padre Fiore.

Aún cuando se pesquise con el mayor rigor histórico, la vida de todo personaje es fragmentaria. No es posible reconstruir en su totalidad -del mismo modo que se arma un rompecabezas-, la historia completa del curso de una vida. No obstante, en el intento de aproximación a la vida y a la dimensión docente y religiosa de Remigio Fiore, se tienen en cuenta diversos hechos históricos, clasificados así: a) Hechos de masas: masas de hombres (rutas migratorias, movimientos poblacionales, asentamientos urbanos, epicentrismo, etcétera); masas de los pensamientos, las creencias y manifestaciones del espíritu (fenómenos de mentalidades, posiciones, opiniones, actitudes, creaciones, etcétera), b) Hechos institucionales que determinan las relaciones sociales dentro de los marcos existentes (derecho civil, constituciones políticas, tratados internacionales, ordenamiento político, sucesos bélicos), c) Acontecimientos en los cuales aparecen y desaparecen personajes y grupos sociales, políticos, económicos, religiosos y culturales determinantes en los cambios ocurridos en la vida regional y nacional, d) Fuentes de consulta: fondos de archivos, fuentes proveídas por historiadores, crónicas.

52. Testimonio escrito de Eraso, Servio Tulio, exprofesor titular de la Universidad de Nariño, actualmente jubilado, colaboró en la revisión de estilo y formulaciones del libro Física del Canguro y los folletos Aventura en el espacio con Arquímedes y Relatividad... qué aventura, autoría de Remigio Fiore Fortezza. Pasto, abril 2 de 2013. 


\section{ARTÍCULOS EN PRENSA, RELATIVOS A PASTO Y LA REGIÓN, AÑOS 1961-1965 (FRAGMENTOS) ${ }^{53}$}

Un viaje por Tierras del Putumayo [...] el trayecto que lleva a la pequeña población de El Encano que es bastante bueno por su arreglo perfecto, que la hace figurar como el primero entre las pocas carreteras buenas que tenemos. En la cadena, que sigue al caserío, termina la carretera y sigue un camino adaptado, estrecho y con desniveles inconsevibles (sic) con las curvas y contracurvas con diámetros reducidos hacen que el viaje sea aburridor y cansado (sic), el tiempo que se gasta hasta la población indígena de Santiago. Viene luego el paraje encantador del Valle de Sibundoy que en un recorrido de unos veinte kilómetros de carretera recta y plana se recrea el viajero con la vista de grandes extensiones de potreros donde pastan ganados vacunos (...) desde allí para adelante, pertenecen a la Comisaría Especial del Putumayo. (...) Aquí el viajero empieza a sentir la transformación total no sólo de sus habitantes que en su gran mayoría pertenecen a poblaciones y ciudades del norte que acosados por la violencia salieron en busca de tranquilidad y la encontraron en grandes dosis: ya que allí, precisamente termina la cordillera oriental para no volverla a ver en cientos de kilómetros que hay para abajo [...] $]^{54}$.

Campaña en Favor de la Ciudad Universitaria. Recibimos con suma satisfacción una invitación que nos hace el señor secretario de la Universidad de Nariño doctor Eraso Gallardo, para que nos sumemos al patriótico y justo anhelo del rector de la Universidad de Nariño, de sus colaboradores y educandos, a luchar tesoneramente para que el parlamento dedique una cantidad suficiente para continuar la construcción de la Ciudad Universitaria de Nariño (...) Esta es la solicitud que hacen los directivos de la Universidad de Nariño a los padres de la patria, quiera Dios y la patrona de Pasto, que la razonada, patriótica y justa petición, rompa los oídos sordos de los que representan al pueblo de nuestro departamento, en las corporaciones nacionales. La Universidad de Nariño con sus Facultades de Derecho y Ciencias Políticas, Bachillerato masculino y femenino, de Agricultura, de Idiomas, de Música y otras necesita una ciudad blanca como las hay en otras capitales de regiones colombianas. TEXTO DEL MENSAJE “Muy encarecidamente solicitámosle acuerdo demás Parlamentarios Nariño, destinar Ley Fomento suma de importancia entre ciento cincuenta y doscientos mil pesos cada senador o representante, fin configurar entre todos auxilio permita atender programas construcción Ciudad Universitaria en lote recientemente adquirido y consolidación distintas dependencias. (...) Atento

53. Todas las crónicas proceden del periódico El Universal, Pasto, años 1961-1965. Periódico liberal.

54. Segundo Meza. "Un viaje por tierras del Putumayo", El Universal, San Juan de Pasto, 1, Octubre, 1961, 2 y 4 [cursivas añadidas]. 
saludo, Luis Santander, rector; Consejo superior, (...) Consejo Directivo, (...) Luis Eduardo Mora Osejo, Directores Liceo: (...), Directores Escuelas Artes (...) ${ }^{55}$.

Gotas de tinta. Por los barrios de Pasto. El bautizado con el nombre de "Lorenzo de Aldana" y calificado con la frase de "Barrio Modelo", está habitado por gentes honestas, trabajadoras y dignas de todo respeto y consideraciones superiores de toda clase. (...) En el barrio Lorenzo de Aldana viven gentes de la clase media, es decir, la que tiene que vestir y vivir como las clases ricas, pero no tiene lo [los] suficientes recursos pecuniarios para sostener estas apariencias tiránicas del construo (sic), que se llama sociedad (...) a las ocho de la noche este barrio se parece a una caverna infernal, porque queda bajo el imperio de la oscuridad; apenas se divisan luces de un candil, una esperma o una lámpara: toda actividad queda suspendida porque sus moradores, necesariamente tienen que encerrarse en sus habitaciones a sufrir la tortura de la noche sin luz, negras como las de los condenados, a las torturas más espantosas que haya podido inventar la tiranía y la injusticia. Por fortuna en este barrio, no hay antisociales, de lo contrario, ya a sus moradores los habrían pasado "al papayo", como en la infortunada Cuba (...) ${ }^{56}$.

La auténtica Universidad [...] Una verdadera y completa educación superior no es posible sin una investigación seriamente organizada, y de aquí que la aludida asamblea de universidades haya decidido conceder también tanta importancia a este punto, en sus largas y bien encauzadas deliberaciones. (...) Naturalmente, un objetivo tan vasto y prometedor no puede lograrse sin un profesorado altamente capacitado y de tiempo completo [...] ${ }^{57}$.

Reportaje al P. Jaime Alvarez S.J. [...] PREGUNTA: Rev. padre, cree Ud. que hay comunismo en la Universidad de Nariño? Y en caso afirmativo, para conjurar ese peligro, qué medidas sugeriría su Reverencia? [R:] La Universidad de Nariño, como la mayoría de las universidades colombianas y de América, ha sido también víctimas de la infiltración castro-comunista. Elementos foráneos, secundados por algunos estudiantes nariñenses, trabajan activamente en la organización de un núcleo más o menos fuerte de agitación Marxista. Su capataz es un joven de otro departamento, inteligente, entrenado, buen organizador, muy servicial y activo, sin afanes para concluir sus estudios de agronomía, tiene mística y espíritu de sacrificio, las brujas hablan de 30 dólares mensuales que le envían, y dispone de mucho tiempo, pues sólo asiste a tres clases teóricas y tres prácticas, quizás un caso único en la facultad. (...) PREGUNTA: Padre, se han lanzado por varios sacerdotes fundamentales reformas sociales que coinciden con las propuestas por el misionero jesuita

55. Comité editorial, “Campaña en favor de la Ciudad Universitaria”, El Universal, Pasto, 1, Diciembre, 1963, 4 [cursivas añadidas].

56. Columna Gotas de Tinta, "Por los barrios de Pasto". El Universal, Pasto, 24, noviembre, 1963, 3.

57. Luis Osorio Castillo, "La auténtica Universidad", El Universal, Pasto, 22, diciembre, 1963, 2. 
P. Huelin, aceptadas por la autoridad eclesiástica. Qué opinión tiene S. R. [su reverencia] al respecto? [R:] A qué sacerdote se refiere Ud. doctor Guzmán: Podría ser al P. Torres. (...) En cuanto al señor Camilo Torres (y digo así porque ya está por su propia voluntad reducido al estado laical, su plataforma social ha sido suficientemente refutada en sus principales planteamientos por eminentes sociólogos (...) Es que, óiganlo muy bien todos, la Iglesia no vetó al entonces P. Torres porque estuviera protestando contra la injusticia. (...) Eso es falso. Si fuera verdad, la iglesia hubiera atajado al P. García Herreros, al P. Salcedo, al P. Lombardi y a muchos otros sacerdotes que en todo el mundo trabajan esforzadamente por el pueblo. (...) El pueblo, mis estimados doctores Córdoba y Guzmán, tiene un gran sentido para saber distinguir muy bien entre el buen pastor y el mercenario $[. . .]^{58}$.

Llegó a Ipiales el primer Obispo. Como estaba programado, el 27 de los corrientes, a las tres de la tarde llegó (sic) al aeródromo de San Luis en un avión oficial el Nuncio Apostólico de Su Santidad Paulo VI, Excelentísimo José Paupini y el Ilustrísimo señor Obispo de Ipiales, Miguel Ángel Arce Vivas. En el campo se había congregado una inmensa multitud de fieles de todos los Municipios de la antigua Provincia de Obando, que lo saludó con aplausos, vivas y pañuelos blancos. También se encontraban representantes de las autoridades civiles, militares y eclesiásticas. A poco rato se inició un gran desfile de automóviles; en los bordes de la carretera, se habían aprestado infinidad de gentes que le ofrecían flores y palmas [...] ${ }^{59}$.

La Turbación del Orden Público. Después de una prolongada deliberación que duró desde las primeras horas del día 20 hasta las cuatro de la madrugada del siguiente, entre los miembros del Gabinete ministerial, los directorios políticos, y el Consejo de Estado, que impartió su aprobación, por decreto $\mathrm{N}^{\circ}$ 1188, fue declarado turbado el orden público y en Estado de Sitio en todo el territorio nacional. Esta medida planeada desde hace algún tiempo y esperada por la opinión honesta como una medida salvadora de la catástrofe, que amenaza la vida misma del país, fue recibida con beneplácito [...] ${ }^{60}$.

\section{HECHOS SIGNIFICATIVOS EN LA REGIÓN, A PARTIR DE 1966}

\subsection{Polémica en torno a la labor de las misiones}

En el año de 1968, Víctor Daniel Bonilla, publica el libro Siervos de Diosy Amos de Indios, dando lugar a una fuerte polémica entre historiadores, indigenistas

58. Córdoba (sin nombre) y Guzmán (sin nombre), “Reportaje al P. Jaime Alvarez, S. J.", El Universal, Pasto, 5, septiembre, 1965, 2 y 4.

59. Comité editorial, “Llegó a Ipiales el Primer Obispo", El Universal, Pasto, 31, enero, 1964, 1 y 4 [cursiva añadida].

60. Comité editorial, "La turbación del Orden Público", El Universal, Pasto, 23, mayo, 1965, 1 [cursiva añadida]. 
y miembros de las órdenes religiosas. El libro, pretendía constituirse en documento histórico de los hechos, presuntivamente desconocidos por la nación, relativos a la labor de los Misioneros Capuchinos en la región del Putumayo. En el libro, se acusa a la Misión Capuchina de múltiples actos de maltrato, explotación y abuso a los indígenas. Los antecedentes históricos del hecho denunciado, acontecen en la vasta extensión geográfica del Putumayo y Caquetá, la cual había sido confiada por el Gobierno a finales del siglo XIX, en 1896, a la Misión Capuchina. La misión, hizo presencia en la zona hasta 1932. Como Inspector General de Instrucción pública, desde 1914 a 1929, el padre Fidel de Montclar, desarrolló "con plenos poderes, casi puestos en sus manos por las Leyes de Colonización y de Gobierno de los indios (...) Las selvas del Caquetá y Putumayo, a su contacto, laten con nueva vida: mejor dicho, despiertan de un letargo que duraba más de un siglo"61. La dinámica de trabajo de Fidel de Montclar, se caracteriza por "trabajar con el mayor celo y eficacia con la misión católica capuchina, con los hermanos maristas, con las madres franciscanas y con un grupo de maestros seglares, por la catequización e instrucción de los habitantes de esta comarca"62. A la llegada de los misioneros, el Putumayo se encontraba habitado por numerosas etnias: coreguajes, enos, tetetes, hachotes, muinanes, jairuyas, jaihones, ingas, cofanes, sionas, huitotos, macaguajes, sebuas, caimitos, pacuyos. La misión capuchina promovió la colonización de la región, para lo cual fue preciso abrir caminos, fundar pueblos y escuelas. Los capuchinos integrantes del equipo misional, eran catalanes. Cuando se habla de capuchinos 'catalanes', no se indica primariamente a los nativos de Cataluña, sino a los "capuchinos integrados a esa provincia regular, -en la cual hubo como misioneros: catalanes, suizos, guatemaltecos, costarricenses, colombianos y ecuatorianos-" 63 .

El equipo liderado por el padre Fidel de Montclar, emprendió y construyó la apertura del camino nacional para caballerías desde Pasto hasta Puerto Asís. La ruta trazada desde Pasto, continúo en los tramos La Laguna-El EncanoSantiago-Sucre [actualmente Colón]-Sibundoy-San Francisco-Mocoa-UmbríaPuerto Asís. El investigador Bonilla, en el citado libro, describe la pobreza y la "explotación" a la cual se sometieron las comunidades Inga del Putumayo: "de manera explícita y descarnada, denunciaba a las misiones capuchinas por haber usufructuado los territorios indígenas Inga a favor de las misiones"64. La denuncia de Bonilla, le abrió un espacio en los círculos de académicos y le permitió asistir en calidad de invitado, a un Consejo Mundial de Iglesias

61. Vilanova, Capuchinos catalanes en el sur de Colombia, 13.

62. Vilanova, Capuchinos catalanes en el sur de Colombia, cita en nota al pie 14, 125.

63. Padre Ramón Vidal, "Siervos de Dios y amos de indios a la luz de la crítica histórica", Cultura Nariñense, vol. 3. No. 25 (1970), 80.

64. Mauricio Caviedes. Metodologías que nos avergüenzan: la propuesta de una investigación en doble vía y su efímera influencia en la antropología (Bogotá, Pontificia Universidad Javeriana, 2013), http:// revistas.javeriana.edu.co/index.php/univhumanistica/article/view/5960 (12 de junio de 2013). 
(CMI). En ese encuentro, activistas de derechos civiles, denuncian a su vez, la participación del CMI en la discriminación y el racismo contra minorías étnicas. De acuerdo con declaraciones de Bonilla, el "crecimiento en la importancia otorgada a los movimientos étnicos durante las últimas décadas del siglo XX inició con aquella denuncia"65. La denuncia de Bonilla plantea una reforma agraria justa a favor del pueblo Inga, capaz de revertir la situación de miseria y mortalidad infantil que sufrían a finales de la década del 60, los indígenas de la región.

Desde la publicación del libro en 1968, el padre Jesuíta Jaime Álvarez, lidera en Pasto una campaña para desmentir las afirmaciones de Bonilla a través de los medios de comunicación de propiedad de la Orden Jesuita: radiodifusión (emisora Ecos de Pasto) y medios escritos (revista cultura nariñense), campaña que tuvo una duración aproximada de 2 años ${ }^{66}$.

\subsection{Presencia de Intelectuales}

Durante la década de 1960-1970 se asiste a la irrupción en el Departamento, de un grupo de intelectuales llegados de otras regiones del país y del mundo, quienes participaron como docentes en diferentes programas y facultades de la Universidad de Nariño, en momentos de plena agitación del movimiento estudiantil que recorría las ciudades latinoamericanas. Profesores e investigadores de economía, ciencias sociales, filosofía, matemáticas, física, literatura, lingüística, sociología, francés, como: Remigio Rosario Fiore Fortezza, Socorro Betancourt, José Miguel Wilches, William Uribe Parra, Alvaro Molina Mallarino, Gustavo Álvarez Gardeazábal (...), Claude Toulliou (...), Harold Alvarado Tenorio, Humberto Márquez Castaño (...), Anne Marie Sallanave, León Zuleta Ruiz, Bruno Mazzoldi (.... ${ }^{67}$ (...) Nicolás Civetta (Italiano), Wolfgang Meyerson (Alemán), Gastone Lanzon (Italiano), Arthur L. Simons (Belga), Federico Povedano y Encarnación de Povedano (Españoles), Rodolfo Avila (Boliviano), C. Busgo (Polaco) ${ }^{68}$.

\section{HECHOS SIGNIFICATIVOS EN EL PAÍS, A PARTIR DE 1966. ENFOQUE DE LA EDUCACIÓN PÚBLICA}

\subsection{Concordato de 1976}

Históricamente, en el marco de la enseñanza en Colombia, en la Constitución de 1886 se determina que el Estado realiza la inspección, pero la Iglesia define

65. Caviedes, Metodologías que nos avergüenzan: la propuesta de una investigación en doble vía y su efímera influencia en la antropología [entrevista a Víctor Daniel Bonilla], 6.

66. Vidal, "Siervos de Dios y amos de indios a la luz de la crítica histórica", 37-38.

67. Javier Rodrizales, Antología de poetas y narradores nariñenses (Pasto: Xexus Edita, 2004), 32-33.

68 Gabriela Hernández Vega, La mujer en la Universidad de Nariño: 1935-1969 (Pasto: Universidad de Nariño, 2004), 142. 
los contenidos. Sólo la reforma del Concordato en 1976, le quitó la injerencia a la Iglesia. Corresponde a la reforma de 1994, haber liberado la educación del control de la Iglesia y del Estado ${ }^{69}$. Por otra parte, las décadas de 1960 y 1970, fueron el escenario de la implantación de la tecnología educativa y del diseño instruccional con lo que se denominó en Colombia, la "renovación curricular". En ese contexto histórico, cabe mencionar el movimiento pedagógico, al dinamizarse la disputa entre diversos actores (maestros, intelectuales de la educación) y las políticas educativas del Estado Colombiano ${ }^{70}$.

\subsection{Reflexión y acción pedagógica}

En palabras del investigador José Fernando Ocampo, "la esencia de la Ley General de Educación reside en la autonomía escolar. Y si se le adiciona el derecho a la libertad de cátedra consagrado en la Constitución de 1991 como el derecho exclusivo de todo maestro, se convierten en la mayor transformación de la educación colombiana en toda su historia"71.

Adquiere particular relevancia, el Grupo de Investigación Educativa de la Universidad Nacional o Grupo Federici, que trabajó en la Universidad Nacional durante toda la década del 80; grupo orientado inicialmente por el también italiano, Carlo Federici Casa quien, en el momento de la conformación del grupo, era director del Instituto de Pedagogía de la Universidad Nacional. El grupo, estuvo constituido por Carlo Federici Casa, pionero de la enseñanza de matemáticas y ciencias naturales en Colombia, Antanas Mockus, Jorge Charum, Berenice Guerrero, María Clemencia Castro, Carlos Augusto Hernández y José Granés. Posteriormente fue coordinado por Antanas Mockus ${ }^{72}$. El Grupo, presentó serios planteamientos diagnósticos, propuestas pedagógicas innovadoras y constituyó semillero de ideas educativas a nivel nacional.

\section{CRONOLOGÍA Y NOTAS DE CARACTERIZACIÓN. PRODUCCIÓN BIBLIOGRÁFICA DEL PADRE FIORE}

1968. Relatividad al alcance de todos. En mimeógrafo. Pasto: Universidad de Nariño. Las ideas fundamentales del documento, se divulgaron en conferencias realizadas por Remigio Fiore en varias instituciones educativas de Colombia, Ecuador e Italia. ${ }^{73}$

69. José Fernando Ocampo, La educación colombiana. Historia, realidades y retos (Bogotá: Magisterio, 2002), 19.

70. Miguel Ángel Gómez Mendoza, "La crítica al "cientificismo" y al "positivismo" en la obra del Grupo de Investigación Educativa de la Universidad Nacional: una mirada desde la teoría crítica", Educación y pedagogía, Vol. IX-X, No. 19 y 20 (septiembre 1997-abril 1998), 33.

71. Ocampo, La educación colombiana. Historia, realidades y retos, 19.

72. José Granés y Carlos Augusto Hernández, "Cultura escolar y cultura extraescolar. Rupturas y continuidades", Educación y pedagogía, Vol. IX-X, No. 19 y 20, (septiembre 1997-abril 1998), 15.

73. Las referencias a la divulgación internacional, figuran en la presentación de Relatividad ... qué aventura [Anotación del autor]. 
1976. Balanzas Planetarias. En mimeógrafo. Pasto: Universidad de Nariño. ${ }^{74}$ Se transcribe la presentación: Con esta publicación de "Balanzas Planetarias" se quiere llevar a nivel de bachillerato, en manera sencilla y clara, los métodos empleados en Astronomía para medir las masas de los Planetas, para que nuestros jóvenes se den cuenta de la facilidad e importancia de los cálculos, que en primera instancia aparecen como misteriosos y sofisticados, cuando se saben fijar bien los conceptos y emplear oportunamente las fórmulas analíticas de la Física. Las matemáticas, bien conocidas, son las mejores compañeras de la investigación exhaustiva de la Naturaleza [Firmado] Dr. Remigio R. Fiore.

1979. Einstein al alcance de todos. En mimeógrafo. Pasto: Universidad de Nariño. Se transcribe la presentación: Esta nueva edisión (sic) de RELATIVIDAD ESPECIAL PARA TODOS, se debe a la conmemoración del primer centenario del nacimiento del padre de la relatividad, Albert Einstein ocurrido en Ulm (Alemania Federal) en el año 1879, 14 de marzo. A la edisión (sic) anterior, ahora se añade un capítulo nuevo: "Derivación simple de las fórmulas de transformación de Lorentz-Fitzgerald" según Einstein; empleando las mismas palabras del Autor. Se ha dicho esto para que el autor se de cuenta como los verdaderos sabios con la sencilles (sic) de unas fórmulas saben expresar la sencilles (sic) y precisión de las leyes que rigen la actividad en la naturaleza. Además, se presenta unos datos cronológicos de la vida de Einstein [Firmado] Dr. Remigio Fiore. ${ }^{75}$

1979. Astronomía. En mimeógrafo. Pasto: Universidad de Nariño. En la Bibliografía citada, figuran libros de astronomía y astrofísica, editados entre 1952 y 1970, en lengua italiana e inglesa, lo cual permite determinar el notable nivel de actualización de sus conocimientos y la labor de traducción al español.

1985. Física y matemáticas. En mimeógrafo. En la introducción se lee: Se ha publicado este "CURSO DE FÍSICA MODERNA" para que los alumnos de Octavo Semestre, en la Especialidad de Matemáticas y Física de la Facultad de Ciencias de la Educación de la Universidad de Nariño, puedan tener en un conjunto orgánico, todas las clases dictadas de Física Moderna [Firmado] Dr. Remigio R. Fiore F. Las referencias bibliográficas, van desde 1920 a 1970.

74. La reimpresión de esta obra, se realiza en marzo de 1979 en el número 21-22 de la Revista Meridiano, 81-103. Órgano de la Facultad de Educación de la Universidad de Nariño. Decano de la Facultad de Educación, Pedro Pablo Cabezas. Director de la Revista, Alberto Quijano Guerrero, padre de Alberto Quijano Vodniza, actual director del Observatorio de la Universidad de Nariño.

75. En la portada del documento, se lee: Universidad de Nariño, Departamento de Ingeniería y Física. Fortunato Pereira Gamba, geólogo, minerologista, matemático, ingeniero y literato, fue el iniciador y fundador de la Facultad Nacional de Ingeniería de la Universidad de Nariño. Con Fortunato Pereira Gamba vino también a la Universidad de Nariño, el geógrafo y matemático de fama continental, Jorge Álvarez Lleras. Pereira Gamba y Álvarez Lleras, citados en: Alfonso Rebolledo Pérez, "Discurso al inaugurar la Galería de Rectores y Profesores de la Universidad en las Fiestas Cincuentenarias", Anales de la Universidad de Nariño, Vol. 6, No. 42, Pasto (1955), 59-60. 
1986. Introducción a la Ciencia del Calor. En mimeógrafo. Portada encuadernada con papel lino de 220 gramos, impresión a color. Este libro, es el resultado de la investigación durante el Año Sabático. Colaboró en la revisión de estilo, presentación y corrección de la formulación matemática, Servio Tulio Eraso. En páginas interiores se incluyen fotografías reveladas (reproducción fotográfica de retratos enciclopédicos). Por considerarse de particular interés, al reflejarse la coherencia en el padre Fiore, de los componentes teórico y experimental, se transcriben las páginas números 212 y 213: Una iniciativa.

Cerramos esta reseña sumaria con dos fotos que muestran los dos páneles planos que abastecen de agua caliente (500 Lt. diarios) a los Hnos. de la Comunidad Franciscana-Capuchina del Convento de Santiago de Pasto. Fig. 9.11. La instalación del sistema ha sido realizado por el Hno. Domingo Agnetta con la supervisión del Hno. Remigio Fiore; los páneles los prepararon los talleres ASEA de los Hnos. Perini. El funcionamiento de todo el conjunto es muy satisfactorio; a la salida de los páneles Fig. 9.12, el agua fácilmente logra los $60^{\circ} \mathrm{C}-80^{\circ} \mathrm{C}$ (de acuerdo con el estado del tiempo) y a la entrada en los tanques de distribución (después de un recorrido de $30 \mathrm{~m}$. en tubos de PVC aislados térmicamente con aserrín) el agua tiene la temperatura de $30^{\circ} \mathrm{C}$, eso es $15^{\circ} \mathrm{C}$ por encima de la temperatura ambiente; suficiente para afirmar que el ahorro, en 500 Lts. diarios, para llevarlo, con energía eléctrica a $70^{\circ} \mathrm{C}$, es muy aceptable.

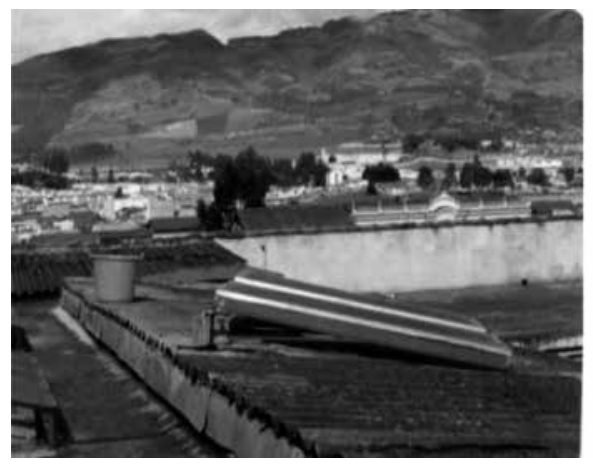

Fig. 9.11

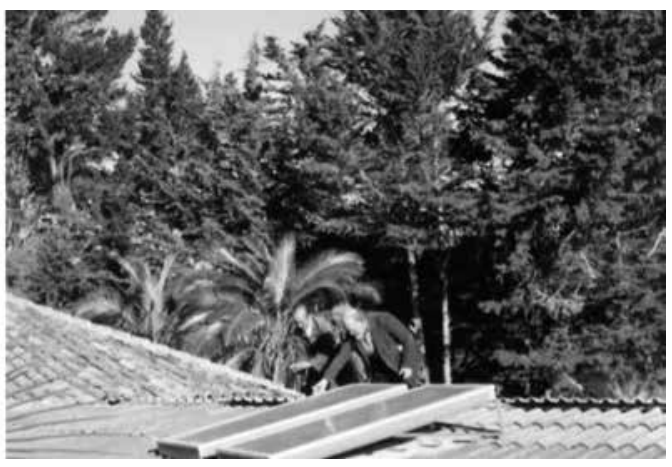

Fig. $9.12^{76}$

1988a. Relatividad...qué aventura. Folleto dirigido a estudiantes de secundaria. En la página reconocimiento, se lee:

(...) Antes que nada, doy gracias a Dios por haberme dado la capacidad de reflexionar y la fuerza de voluntad para dedicarme con entusiasmo,

76. A la derecha, padre Remigio Fiore. A la izquierda, padre Domingo Agnetta. Dimensión de fotografía: $12.5 \mathrm{cms}$ x 9 cms., fecha probable: 1989 . 
constancia y desinterés a redactar unas ideas innovadoras en tópicos de Física poco accesibles a la juventud que apenas se inicia a desentrañar los misterios escondidos en la Naturaleza (...). En la página de presentación, se lee: (...) Espero que este trabajo mueva a los jóvenes y despierte en ellos la inquietud para que en total lleve a físicos y profesores de Física de Mecánica, desde el Bachillerato hasta la Universidad, tomando como modelos los laboratorios de Alta Energía en la época de la Energía Nuclear, que son las exigencias de la Relatividad. [Firmado]. DR. REMIGIO FIORE F. En acápite Charla 6, Algunos Hechos, el autor anota: (...) Si ustedes jovencitos, tienen la oportunidad de entrar a una biblioteca bien dotada, con libros actuales en el campo de la Física, Historia de la Ciencia, realidades industriales, etc., busquen los temas: Laboratorios de alta energía, centrales nucleares, ingeniería nuclear, submarina o atómica. Lean, observen, calculen (...).

1988b.Aventuras en el Espacio con Arquímedes. Folleto dirigido a estudiantes de secundaria. Readaptación de Balanzas Planetarias.

1989. Física del Canguro. En la pág. 52 del libro, se lee: RECOMENDACIONES: 1. Con el propósito de que el alumno logre entender más profundamente los conceptos que se desarrollan en la teoría de la relatividad, se aconseja el estudio de las publicaciones originales que publicó Einstein para difundir sus ideas: The evolution of physics, 1948, La relatividad, colección Dina, 1970, The meaning of relativity, 1950.

(198?) Estudio de la validez de la ecuación de Van Der Walls para Gases reales ${ }^{77}$.

(198?) Física General Experimental (3 Vol.).

(198?) Física Teórica.

(198?) Física Matemática.

(198?) Física Moderna ${ }^{78}$.

1999. Traducción del italiano del libro "Omaggio a Fray Daniele, Capuchino". El padre Remigio Fiore, es sobrino de Fray Daniele Natale (1919?-1994), un sacerdote capuchino que se dedicó a misionar en medio de tierras hostiles, durante la segunda guerra mundial. El libro obtuvo la aprobación eclesiástica de Monseñor Serafino Spreafico, Obispo Capuchino, en el mismo año de la muerte de Remigio Fiore, en 1998. El libro, describe las experiencias que experimentó durante 3 horas en el Purgatorio, Fray Daniele, nacido en San Giovanni Rotondo y compañero de convento del Santo Padre Pío (Pietrelcina, 1887-San Giovanni Rotondo, 1968) 79.

77. Folleto (198?) citado en Fiore, Relatividad... qué aventura (s.p.).

78. Libros (198?) citados en Fiore, Relatividad... qué aventura (s.p.).

79. Pío de Pietrelcina, también conocido como el Padre Pío, religioso capuchino y santo italiano. Famoso por los estigmas que exhibía en las manos. Canonizado en 2002 por Juan Pablo II. En 2012, se abrió una causa de beatificación de Fray Daniele y hoy en día es considerado Siervo de Dios. 


\section{CONCLUSIONES}

Durante el siglo XX, advienen profundos cambios políticos, económicos, culturales y sociales que conducen a la pérdida de la legitimidad de la Iglesia colombiana en la orientación de la enseñanza. No obstante, pese a las condiciones históricas particulares de Pasto, a su posición geopolítica colindante con el Ecuador, la ciudad se caracterizó como un área con influjo fuertemente colonial, hasta bien entrado el siglo XX.

La Universidad de Nariño es el escenario en el cual se inscribe el trabajo pedagógico y franciscano del padre Fiore y por consiguiente, sus reflexiones y su quehacer en el horizonte conceptual de las ciencias naturales. Desde su llegada a la Universidad en 1966, Remigio Fiore se proyecta a lo más avanzado del conocimiento científico en su campo e insiste en la dimensión del legado Einsteniano, mediante la actualización permanente de los contenidos de la Física Moderna. La actualización científica del padre Fiore, es constante durante su vida académica. En reconocimiento y en su memoria, la Universidad de Nariño bautizó con su nombre el laboratorio de Física e instaló una placa honorífica, el 7 de marzo de 1997. En la actualidad, la Biblioteca de la Institución Universitaria Cesmag, lleva su nombre. Para la elaboración del material mimeografiado producido durante su vida académica, el padre Fiore requirió de acopio bibliográfico en varios idiomas (inglés, francés, italiano).

La explotación de la energía solar, constituyó un importante trabajo investigativo de su Profesor en la Universidad de Palermo (Italia), Enrico Mèdi. Con mano de obra local, el padre Fiore instala un panel solar en la ciudad de Pasto en 1986. Se ha verificado a la fecha, enero de 2015, la existencia y funcionalidad del panel solar en la comunidad de los hermanos Capuchinos.

Aún cuando mediante la narratividad, se perfilaron métodos pedagógicos verticales, el enfoque educativo del padre Fiore buscó en esencia, responder a las condiciones regionales, proyectándose a la vigencia del conocimiento científico. Su legado profesoral, enriquece el patrimonio cultural y educativo de la región, al traspasar el entorno local. La educación científica impartida, se reconoce en su capacidad y tenacidad personal al integrar su fe franciscana al servicio de las juventudes: "me queda la satisfacción del deber cumplido y la esperanza de haber sembrado una semilla científica en la mente de tantos jóvenes en formación. Los frutos se cosecharán en los años por venir y la posteridad sabrá valorar su esfuerzo"80.

La metodología empleada por el Profesor Fiore, tanto en las clases como en la producción bibliográfica y en la faceta experimental, está relacionada con

80. Rosario Remigio Fiore Fortezza, Relatividad... qué aventura (Pasto: Instituto Nacional María Goretti, 1988a), sin número, antes de iniciar página de contenido. Aventura en el espacio con Arquímedes. (Pasto: Instituto Nacional María Goretti, 1988b), sin número, antes de iniciar página de contenido. 
el impacto comunicativo de la educación, al identificarse un reconocimiento de la posibilidad de autodeterminación en los exalumnos. Como Capuchino, cumplió con la observancia: "dar a conocer la persona de Jesucristo y su evangelio, aportando preparación y energía para reforzar y mejorar el tejido social, colaborando con el crecimiento y desarrollo de los pueblos"81.

Desde 2008, el Departamento de Física de la Universidad de Nariño, posee acreditación de alta calidad. Forman parte de la Facultad de ciencias naturales y matemáticas, el área de Física y la Licenciatura en matemáticas.

La actividad humana, ya sea intelectual o física, definida por San Francisco como "la gracia de trabajar", le da una connotación teológica y teleológica a la contemplación de la naturaleza: "La Física del Canguro se cierra con un mensaje fuera de texto, dirigido a la juventud que se dedica a la investigación científica, para la utilización adecuada y efectiva de las energías que esconde la Naturaleza en su Modus Operandi, a fin de mejorar y ennoblecer el trabajo del hombre" 82 .

81. Padre Luis Eduardo Rubiano. "Economía y comunión de Bienes. Historia de algunas ideas a la luz de las Ordenes Franciscanas", Tendencias, Vol. XII, No. 2 (2011), 176.

82. Fiore Fortezza, "Física del Canguro", 8. 


\section{REFERENCIAS BIBLIOGRÁFICAS}

Boverio, Zacarías. Primera parte de las Chronicas de los Frailes Menores Capuchinos. Madrid: Carlos Sánchez, 1644, Apéndice “De la verdadera forma de hábito".

Castellar, Manuel. Los Capuchinos en Colombia, 1888-1970. Bogotá: Gráficas Centella, 1970.

Caviedes, Mauricio. Metodologías que nos avergüenzan: la propuesta de una investigación en doble vía y su efímera influencia en la antropología. Bogotá, Pontificia Universidad Javeriana, 2013, http://revistas. javeriana.edu.co/index.php/univhumanistica/article/view/5960.

Ciuffoletti, Zeffiro y dell' Innocente, Mauricio. “L'Emigrazione nella storia d' Italia 1869-1975". En: Acerca de las migraciones centro-europeas y mediterráneas a Iberoamérica: aspectos sociales y culturales, editado por Moisés Minambres. Sin ciudad de edición, sin editorial, 1995, sin páginas del artículo. Citados por Silva, Armando (véase).

Corvera Poiré, Marcela. "Estudio Histórico de la familia de Franciscanos Descalzos en la Provincia de San Diego de México, siglos XVI-XX”. Tesis Doctoral en Doctorado en Historia, Universidad Complutense de Madrid, 1995.

Enciclopedia Treccani. Dizionario Biografico degli italiani. “Enrico Mèdi”, Vol. 73, 2009, http://www.treccani. it/enciclopedia/enrico-medi_(Dizionario-Biografico, (15 de mayo de 2013).

Fiore Fortezza, Rosario Remigio. Padre OHM Cap. Curriculum Vitae. Pasto: julio 20, 1996.

Fiore Fortezza, Rosario Remigio. Padre OHM Cap. Física del Canguro. Pasto: Universidad de Nariño, 1989.

Fiore Fortezza, Rosario Remigio. Padre OHM Cap. Relatividad...qué aventura. Pasto: Instituto Nacional María Goretti, 1988a.

Fiore Fortezza, Rosario Remigio. Padre OHM Cap. Aventura en el Espacio con Arquímedes. Pasto: Instituto Nacional María Goretti, 1988b.

Fiore Fortezza, Rosario Remigio. Padre OHM Cap. Introducción a la Ciencia del Calor. En mimeógrafo, encuadernado. Pasto: Universidad de Nariño, 1986.

Fiore Fortezza, Rosario Remigio. Padre OHM Cap. Física y matemáticas. En mimeógrafo. Pasto: Universidad de Nariño, 1985.

Fiore Fortezza, Rosario Remigio. Padre OHM Cap. Astronomía. En mimeógrafo. Pasto: Universidad de Nariño, 1979.

Fiore Fortezza, Rosario Remigio. Padre OHM Cap. Einstein al alcance de todos. En mimeógrafo. Pasto: Universidad de Nariño, 1979.

Fiore Fortezza, Rosario Remigio. Padre OHM Cap. Balanzas Planetarias. En mimeógrafo. Pasto: Universidad de Nariño, 1976.

Fiore Fortezza, Rosario Remigio. Padre OHM Cap. Relatividad al alcance de todos. En mimeógrafo. Pasto: Universidad de Nariño, 1968.

Gálvez, Tomás (Fray). Sitio oficial de los hermanos menores capuchinos. Los frailes de la "vida eremítica" o capuchinos. 2002, http://www.fratefrancesco.org/ord/64.cap.htm.

García y García, Antonio. "La donación pontificia de las Indias”. En Historia de la Iglesia en Hispanoamérica y Filipinas (siglos XV-XIX), editado por Borges, Pedro. Madrid: Biblioteca de Autores Cristianos, Estudio Teológico de San Ildefonso de Toledo, 1992.

Granés, José y Hernández, Carlos Augusto. “Cultura escolar y cultura extraescolar. Rupturas y continuidades”. Educación y Pedagogía, Vol. IX-X, No. 19 y 20 (septiembre 1997-abril 1998). 
Guerrero Vinueza, Gerardo León. “Análisis socioeconómico de Pasto a finales del período colonial”. En: Pasto 450 Años. Historia y cultura, compilado por Yie Polo, Alvaro. Quito: Instituto Andino de Artes Populares del convenio “Andrés Bello" y Universidad de Nariño, departamento de Filosofía y Humanidades, 1988.

Henao, Jesús María y Arrubla, Gerardo. Compendio de la Historia de Colombia. Bogotá: Librería Voluntad, 1910.

Hernández Sotelo, Anel. “El prodigioso hábito capuchino. Construcciones y violencia simbólica en la escritura de Zacarías Boverio”. Dimensión Antropológica, vol. 55 (mayo-agosto, 2012).

Hernández Vega, Gabriela. La mujer en la Universidad de Nariño: 1935-1969. Pasto: Universidad de Nariño, 2004.

Mendoza, Pedro. Mi memoria histórica (1948-1988). Alicante: Ediciones Pedro Mendoza, 2010.

Misioneros Capuchinos. Historia de los Capuchinos en Colombia, http://www.capuchinoscolombia.com/ capuchinos.html.

Molano Bravo, Alfredo. "La gente no habla en conceptos a menos que quiera esconderse". En: Memorias 2010, Ponencias, editado por Asociación para el Desarrollo Campesino, ADC (Pasto, 2010).

Molinari, Diego Luis. Descubrimiento y conquista de América. Buenos Aires: Eudeba, 1964.

Narváez Ramírez, Guillermo Alfredo. "Aspectos fundamentales de la economía de Pasto y Nariño", Pasto 450 Años. Historia y cultura, compilado por Alvaro Yie Polo. Quito: Instituto Andino de Artes Populares del convenio "Andrés Bello" y Universidad de Nariño, departamento de Filosofía y Humanidades (1988).

Natale, Daniele. Omaggio a Fray Daniele, capuchino. Traducido por padre Remigio Fiore. Madrid: Sol de Fátima, 1999.

Ocampo, José Fernando. La educación colombiana. Historia, realidades y retos. Bogotá: Magisterio, 2002.

Rebolledo Pérez, Alfonso. "Discurso al Inaugurar la Galería de Rectores y Profesores de la Universidad en las Fiestas Cincuentenarias". Anales de la Universidad de Nariño, Vol. 6. No. 42 (1955).

Rodrizales, Javier. Antología de poetas y narradores nariñenses. Pasto: Xexus edita, 2004.

Rubiano, Luis Eduardo. Padre OHM Cap. "Economía y comunión de Bienes. Historia de algunas ideas a la luz de las Ordenes Franciscanas”. Tendencias, Vol. XII, No. 2 (2011).

Sañudo, José Rafael. Apuntes sobre la historia de Pasto. La colonia bajo la casa de Borbón. Pasto: imprenta La Nariñesa, 1940.

Silva, Armando. Cultura italiana en Colombia. Reflexión sobre etnias y mestizajes culturales. Bogotá: Tercer Mundo Editores e Istituto Italiano di Cultura, 1999.

Triana, Miguel. Por el sur de Colombia. Excursión pintoresca y científica al Putumayo. París: Garnier Hermanos, 1908.

Universidad de Nariño. Prospecto general de la Universidad de Nariño. Pasto: Intergráficas, 1963.

Vidal, Ramón [Padre capuchino]. "Siervos de Dios y amos de indios a la luz de la crítica histórica”. Cultura Nariñense. Vol. 3. No. 25 (1970).

Vilanova, Pacífico de. Padre OFM Cap. Capuchinos catalanes en el Sur de Colombia. II parte. Barcelona: Imprenta Myria, 1947.

Wikipedia, la enciclopedia libre. Persecuciones a la Iglesia católica en la Segunda Guerra Mundial y a Pío XII. Wikipedia, 2014.

http://es.wikipedia.org/wiki/Persecuciones_a_la_Iglesia_Cat\%C3\%B3lica_en_la_Segunda_Guerra_ Mundial_y_a_P\%C3\%ADo_XII. 
Zarama, José Rafael. Reseña Histórica. Pasto: Imprenta del Departamento, 1942.

Zarama Delgado, Manuel. “Algunos Europeos en Pasto, II Parte”. En: Manual Historia de Pasto, Tomo V. Pasto: Alcaldía Municipal de Pasto-Oficina Municipal de Cultura, 2002.

\section{Periódicos}

Columna Gotas de Tinta. “Por los barrios de Pasto”. El Universal, Pasto, 24, noviembre, 1963.

Comité editorial El Universal. “Campaña en favor de la Ciudad Universitaria”. El Universal, Pasto, 1, Octubre, 1963.

."Llegó a Ipiales el Primer Obispo", El Universal (Pasto, 31, enero, 1964).

“La turbación del Orden Público", El Universal (Pasto, 23, mayo, 1965).

Córdoba (sin nombre) y Guzmán (sin nombre). "Reportaje al P. Jaime Alvarez, S. J.”, El Universal (Pasto, 5, septiembre, 1965).

Gaceta del Huila, Neiva, 19 de junio de 1907. Cita extraída de: Tovar Zambrano, Bernardo. La Economía Huilense entre la Tradición y la Modernidad (1900-1960), tomo III, 96. Huila: Instituto Huilense de Cultura, 1996.

Meza, Segundo. “Un viaje por tierras del Putumayo”. El Universal (San Juan de Pasto, 1, Octubre, 1961).

\section{Entrevistas a exalumnos de Remigio Fiore}

Entrevista a Cabezas, Pedro Pablo. Comunicación personal. Pasto, 8 de marzo de 2013.

Entrevista a Erazo, Servio Tulio. Comunicación escrita. Pasto, 2 de abril de 2013.

Entrevista a Muñoz Espinosa, Alicia. Grabación. Pasto, 25 de febrero de 2013.

Entrevista a Quijano Vodniza, Alberto. Comunicación escrita. Pasto, 9 de mayo de 2013. 